\title{
Probing the Mechanism of Receptor Activity-Modifying Protein Modulation of GPCR Ligand Selectivity through Rational Design of Potent Adrenomedullin and Calcitonin Gene-Related Peptide Antagonists ${ }^{\mathrm{S}}$
}

\author{
Jason M. Booe, Margaret L. Warner, Amanda M. Roehrkasse, Debbie L. Hay, \\ and Augen A. Pioszak \\ Department of Biochemistry and Molecular Biology, University of Oklahoma Health Sciences Center, Oklahoma City, Oklahoma \\ (J.M.B., M.L.W., A.M.R., A.A.P.) and School of Biological Sciences, University of Auckland, Auckland, New Zealand (D.L.H.)
}

Received October 20, 2017; accepted January 19, 2018

\begin{abstract}
Binding of the vasodilator peptides adrenomedullin (AM) and calcitonin gene-related peptide (CGRP) to the class $B$ G protein-coupled receptor calcitonin receptor-like receptor (CLR) is modulated by receptor activity-modifying proteins (RAMPs). RAMP1 favors CGRP, whereas RAMP2 and RAMP3 favor AM. Crystal structures of peptidebound RAMP1/2-CLR extracellular domain (ECD) heterodimers suggested RAMPs alter ligand preference through direct peptide contacts and allosteric modulation of CLR. Here, we probed this dual mechanism through rational structure-guided design of $A M$ and CGRP antagonist variants. Variants were characterized for binding to purified RAMP1/2-CLR ECD and for antagonism of the full-length CGRP (RAMP1:CLR), AM 1 (RAMP2:CLR), and AM 2 (RAMP3:CLR) receptors. Short nanomolar affinity $\mathrm{AM}(37-52)$ and $\mathrm{CGRP}(27-37)$ variants were obtained through substitutions including AM S45W/ Q50W and CGRP K35W/A36S designed to stabilize their $\beta$-turn.
\end{abstract}

K46L and Y52F substitutions designed to exploit RAMP allosteric effects and direct peptide contacts, respectively, yielded AM variants with selectivity for the CGRP receptor over the $A M_{1}$ receptor. AM(37-52) S45W/K46L/Q50W/Y52F exhibited nanomolar potency at the CGRP receptor and micromolar potency at $\mathrm{AM}_{1}$. A 2.8-A resolution crystal structure of this variant bound to the RAMP1-CLR ECD confirmed that it bound as designed. CGRP(2737) N31D/S34P/K35W/A36S exhibited potency and selectivity comparable to the traditional antagonist CGRP(8-37). Giving this variant the ability to contact RAMP2 through the F37Y substitution increased affinity for $\mathrm{AM}_{1}$, but it still preferred the CGRP receptor. These potent peptide antagonists with altered selectivity inform the development of AM/CGRP-based pharmacological tools and support the hypothesis that RAMPs alter CLR ligand selectivity through allosteric effects and direct peptide contacts.

\section{Introduction}

Adrenomedullin (AM) and calcitonin gene-related peptide (CGRP) are related vasodilator peptides that have overlapping

The coordinates and structure factors for the AMmut-bound MBP-RAMP1 ECD-CLR ECD fusion protein were deposited with the worldwide protein data bank with ID code 5V6Y.

Peptide variants described in this manuscript are the subject of a patent application (AAP).

This work was supported by grants from the National Institutes of Health [R01GM104251] and the Oklahoma Center for the Advancement of Science and Technology [HR16-005] (A.A.P.). The microscope used for crystal imaging was supported by an Institutional Development Award (IDeA) from the National Institute of General Medical Sciences of the NIH [P20GM103640]. The Advanced Photon Source is a US Department of Energy Office of Science User Facility operated for the DOE Office of Science by Argonne National Laboratory under Contract No. DE-AC02-06CH11357. Use of LS-CAT sector 21 was supported by the Michigan Economic Development Corporation and the Michigan Technology Tri-Corridor [Grant 085P1000817]. D.L.H. is supported by a James Cook Research Fellowship from the Royal Society of New Zealand.

https://doi.org/10.1124/mol.117.110916.

S This article has supplemental material available at molpharm. aspetjournals.org and distinct functions in human physiology and pathophysiology (Russell et al., 2014; Kato and Kitamura, 2015; Klein and Caron, 2015). AM signaling is critical during development, as mice lacking AM or its receptor components were embryonic lethal due to cardiovascular and lymphatic defects (Caron and Smithies, 2001; Shindo et al., 2001; Dackor et al., 2006; Fritz-Six et al., 2008). AM is produced by endothelial and vascular smooth muscle cells. Circulating AM levels are elevated in various diseases, including myocardial infarction and heart failure, where it has cardioprotective effects. Additional AM functions include lymphatic maintenance and anti-inflammatory activity. CGRP is a neuropeptide released from perivascular sensory nerves where it acts as a microvascular vasodilator (Russell et al., 2014). CGRP has cardioprotective effects and is involved in migraine headache pathogenesis through its unique role in the trigeminovascular system (Russell et al., 2014; Russo, 2015; Edvinsson, 2017).

There is considerable interest in developing therapeutics targeting AM and CGRP signaling. Agonism of AM signaling

ABBREVIATIONS: Ahx, aminohexanoic acid; AM, adrenomedullin; AMmut, AM(37-52) $\mathrm{NH}_{2} \mathrm{~S} 45 \mathrm{~W} / \mathrm{K} 46 \mathrm{~L} / \mathrm{Q} 50 \mathrm{~W} / \mathrm{Y} 52 \mathrm{~F}$; BSA, bovine serum albumin; CGRP, calcitonin gene-related peptide; CGRPmut, CGRP(27-37) $\mathrm{NH}_{2}$ N31D/S34P/K35F; CLR, calcitonin receptor-like receptor; DMEM, Dulbecco's modified Eagle's medium; ECD, extracellular domain; FITC, fluorescein isothiocyanate; FP, fluorescence polarization; MBP, maltose-binding protein; MR, molecular replacement; RAMP, receptor activity-modifying protein. 
holds promise for cardiovascular disorders, lymphedema, and inflammatory bowel disease, and antagonism of AM signaling may be of value for cancer (Kato and Kitamura, 2015; Klein and Caron, 2015). Agonism of CGRP signaling shows promise for cardiovascular disease (Aubdool et al., 2017), and antagonism of CGRP signaling by small-molecule antagonists of the CGRP receptor or monoclonal antibodies against the CGRP peptide or its receptor showed significant benefit in clinical trials for migraine (Edvinsson, 2015; Tso and Goadsby, 2017). Nonetheless, our understanding of AM and CGRP signaling is still limited because AM and CGRP share three highly similar heterodimeric receptors. These are composed of a common class B G protein-coupled receptor subunit, the calcitonin receptor-like receptor (CLR), and one of three variable receptor activity-modifying protein (RAMP1-3) subunits that alter CLR ligand selectivity (McLatchie et al., 1998; Hay and Pioszak, 2016). RAMP1 confers a preference for CGRP, and its complex with CLR is designated the CGRP receptor. RAMP2 and RAMP3 favor AM, and their complexes with CLR are designated the $\mathrm{AM}_{1}$ and $\mathrm{AM}_{2}$ receptors, respectively. Understanding the mechanistic basis for RAMP modulation of CLR pharmacology is crucial to harness the potential of this system for novel therapeutics.

CLR has an N-terminal extracellular domain (ECD) and a 7-transmembrane helical bundle domain. RAMPs have an $\mathrm{N}$-terminal ECD and a single-transmembrane helix. AM and CGRP bind the heterodimeric receptor complexes through a "two-domain" model (Barwell et al., 2012). The C-terminal half of the peptide binds the ECD complex, and the N-terminal half binds and activates the CLR 7-transmembrane domain. N-terminally truncated peptides thus act as competitive antagonists (Chiba et al., 1989). CGRP(8-37) and AM(22-52) antagonists have traditionally been used to discriminate the CGRP and $\mathrm{AM}_{1 / 2}$ receptors, but these are only moderately selective. Antagonists that discriminate the $\mathrm{AM}_{1}$ and $\mathrm{AM}_{2}$ receptors are lacking. Consequently, it is not always clear which receptor mediates a given peptide effect.

The peptide selectivity profiles of the CGRP and $\mathrm{AM}_{1}$ receptors were recapitulated by purified soluble ECD heterodimers engineered as tethered RAMP ECD-CLR ECD fusion constructs (Moad and Pioszak, 2013). Crystal structures of tethered RAMP1-CLR ECD and RAMP2-CLR ECD with bound antagonist fragments of the high-affinity CGRP N31D/S34P/K35F variant (Rist et al., 1998) and AM, respectively, revealed that the peptides occupy a shared binding site on CLR and make limited contact with the RAMPs (Booe et al., 2015). The RAMPs augment a pocket occupied by the peptide C-terminal residue such that RAMP1 W84 contacts CGRP F37 and RAMP2 E101 hydrogen bonds with AM Y52. The two structures also revealed subtle conformational differences in CLR, which suggested a possible allosteric component to RAMP function.

We hypothesized that the mechanism of RAMP modulation of CLR ligand selectivity could be explored with AM and CGRP variants bearing amino acid substitutions designed to probe the putative RAMP allosteric effects and direct peptide contacts. Guided by the structures (Booe et al., 2015), we designed short high-affinity antagonist variants and then used these as scaffolds in which to add substitutions probing the RAMP mechanism. We characterized the binding of the variants to tethered RAMP-CLR ECD proteins and their antagonism at intact receptors, and used X-ray crystallography to confirm that an AM variant designed to have altered preference for the CGRP receptor bound as designed. Our results inform efforts to develop novel AM/CGRP-based pharmacological tools and therapeutics and support a dual mechanism for RAMP modulation of CLR ligand selectivity comprising both allosteric and direct peptide contact components.

\section{Materials and Methods}

Reagents. General laboratory chemicals were from Sigma-Aldrich (St. Louis, MO). Dulbecco's modified Eagle's medium (DMEM) 4.5 g/l glucose, L-glutamine was from Lonza (Basel, Switzerland). Fatty-acidfree bovine serum albumin (BSA) was from PAA Laboratories. Fetal bovine serum was from Life Technologies (Carlsbad, CA). Sodium malonate, $\mathrm{pH}$ 6.0, was from Hampton Research (Aliso Viejo, CA). COS7 cells were from American Type Culture Collection (Manassas, VA) (CRL-1651).

Plasmids. All plasmids used the human RAMP and CLR sequences. The pETDuet-1 plasmids for bacterial expression of maltose-binding protein (MBP)-RAMP1.24-111-(GSA) ${ }_{3}-$ CLR.29-144- $\mathrm{H}_{6}$ and MBPRAMP1.24-111-(GS) $)_{5}$ CLR.29-144- $\mathrm{H}_{6}$ were previously described (Moad and Pioszak, 2013; Booe et al., 2015). The pETDuet-1-based plasmid encoding MBP-RAMP2.55-140[L106R]-(GS) ${ }_{5}-$ CLR.29-144-H 6 was constructed using Gibson Assembly (New England Biolabs, Ipswich, MA) by generating overlapping fragments to replace the (GS) $)_{2}-(\mathrm{RS})-(\mathrm{GS})_{2}$ linker with (GS) $)_{5}$ in the previously reported plasmid MBP-RAMP2.55-140-(GS) $2_{2}$

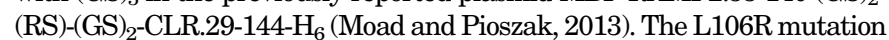
in RAMP2 was introduced by site-directed mutagenesis using the QuikChange II kit (Agilent, Santa Clara, CA) as previously described (Booe et al., 2015). Primer sequences to generate Gibson Assembly fragments and for site-directed mutagenesis are available from the authors upon request. All plasmid sequences were verified by automated DNA sequencing by the University of Oklahoma Health Sciences Center Laboratory for Molecular Biology and Cytometry Research core facility. For transient transfections in COS-7 cells, expression plasmids containing untagged RAMP1-, RAMP2-, RAMP3-, or CLR-encoding sequences in the pcDNA3.1(+) vector were purchased from the Missouri University of Science and Technology cDNA resource center (Rolla, MO), and plasmid DNA was isolated using a Midi kit (Macherey-Nagel) according to the manufacturer's instructions.

Purified Proteins. The MBP-RAMP1.24-111-(GS) $)_{5}$-CLR.29144- $\mathrm{H}_{6}$, MBP-RAMP1.24-111-(GSA) $)_{3}-\mathrm{CLR} .29-144-\mathrm{H}_{6}$, and MBPRAMP2.55-140[L106R]-(GS) $)_{5}$ CLR.29-144-H 6 fusion proteins were expressed in Escherichia coli and purified as previously described (Moad and Pioszak, 2013; Booe et al., 2015). The numbers after RAMP1/2 and CLR indicate the amino acid residues included in the constructs. The RAMP2 L106R substitution prevents dimerization of the tethered construct; this mutation had no effect on the function of the intact $\mathrm{AM}_{1}$ receptor complex in cells (Booe et al., 2015). Purified proteins were dialyzed to storage buffer containing $50 \mathrm{mM}$ Tris-HCl $(\mathrm{pH} 7.5), 50 \%(\mathrm{v} / \mathrm{v})$ glycerol, and $150 \mathrm{mM} \mathrm{NaCl}$ and stored at $-80^{\circ} \mathrm{C}$. The control MBP-thrombin cut site-RSPO4- $\mathrm{H}_{6}$ fusion protein was previously described (Warner et al., 2015). Protein concentrations were determined by Bradford assay with a BSA standard curve, and the concentrations are stated in terms of the fusion protein monomer.

Synthetic Peptides. High-performance liquid chromatographypurified custom synthetic peptides, including human $\operatorname{AM}(13-52)$ and all truncated CGRP and AM variants used in this study, were purchased from RS Synthesis (Louisville, KY). Human $\alpha$ CGRP (1-37) was purchased from Bachem (Bubendorf, Switzerland). Lyophilized peptides were reconstituted in sterile ultrapure water, and aliquots were stored at $-80^{\circ} \mathrm{C}$. Peptide concentrations were determined by UV absorbance at $280 \mathrm{~nm}$ with molar absorptivity calculated based on tyrosine, tryptophan, and cystine residues. Fluorescein isothiocyanate (FITC)-aminohexanoic acid (Ahx)-AM(37-52) S45W/Q50W concentration was determined by visible absorbance at $495 \mathrm{~nm}$ using the molar absorptivity of the FITC molecule 
( $\varepsilon=72,000 \mathrm{M}^{-1} \mathrm{~cm}^{-1}$ at $\mathrm{pH} 8.0$ ). The concentration of human $\alpha \mathrm{CGRP}$ (1-37) was determined using the reported peptide content from amino acid analysis by Bachem. For peptides that lacked UV-absorbing residues, we assumed $80 \%$ peptide content for the lyophilized powder. The biotinylated peptides used in the AlphaLISA assays were previously described (Moad and Pioszak, 2013). All peptides were amidated $\left(-\mathrm{CONH}_{2}\right)$ at their $\mathrm{C}$ terminus. The sequences of all peptides used in this study are provided in Supplemental Table S1.

AlphaLISA Luminescent Proximity Competition PeptideBinding Assay. This assay was performed as previously described (Lee et al., 2016), except that a $10-\mu \mathrm{g} / \mathrm{ml}$ final bead concentration was used and $0.3 \%(\mathrm{v} / \mathrm{v})$ Triton X-100 was included in the reaction buffer for the MBP-RAMP2 ECD[L106R]-(GS) ${ }_{5}$-CLR ECD fusion protein. In brief, a master mix containing biotin-AM(19-52) C21A or biotin$\alpha$ CGRP(8-37) and purified MBP-RAMP1 or -2 ECD-(GS) $)_{5}$-CLR ECD and streptavidin-coated donor and anti-MBP antibody-coated acceptor beads (PerkinElmer, Waltham, MA) was mixed with unlabeled competitor peptides at the indicated concentrations and incubated for 5 hours in the dark before reading luminescence in a Polarstar Omega plate reader equipped with AlphaLISA filters (BMG Labtech, Ortenberg, Germany). The competition binding curves were fit by nonlinear regression to the "log (inhibitor) versus response (three parameters)" equation in GraphPad Prism 5.0f (GraphPad Software, La Jolla, CA) to determine $\log \mathrm{IC}_{50}$ values. No parameters were shared among data sets and no weighting or constraints were used.

Fluorescence Polarization/Anisotropy Peptide-Binding Assay. This assay was performed as previously described (Lee et al., 2017), except using FITC-Ahx-AM(37-52) S45W/Q50W as the probe, and Tween-20 was omitted from the reaction buffer. Saturation binding used $7 \mathrm{nM}$ FITC-Ahx-AM(37-52) S45W/Q50W and the indicated concentrations of MBP-RAMP1/2 ECD-(GS) 5 -CLR ECD fusion proteins with a 1-hour incubation at room temperature. Anisotropy values were corrected for the slight fluorescence intensity enhancement observed upon receptor binding (Supplemental Fig. S1E) as previously described (Lee et al., 2017). Competition binding assays used $7 \mathrm{nM}$ FITC-peptide and $15 \mathrm{nM}$ MBP-RAMP1 ECD-(GS) $)_{5}$-CLR ECD or $110 \mathrm{nM}$ MBP-RAMP2 ECD-(GS) $)_{5}$-CLR ECD with the indicated concentrations of competitor peptides and a 2-hour incubation at room temperature. Anisotropy values were not corrected for the slight decrease in total fluorescence intensity observed upon probe displacement because determination of the competitor $\mathrm{K}_{\mathrm{I}}$ value is insensitive to minor intensity changes (Roehrl et al., 2004). Equilibrium dissociation constants were determined for the labeled probe from the saturation experiments $\left(\log \mathrm{K}_{\mathrm{D}}\right.$ ) and for the unlabeled peptides from competition experiments $\left(\log \mathrm{K}_{\mathrm{I}}\right)$ by nonlinear regression fitting of the binding curves to the exact analytical equations of Roehrl et al. (2004) using user-defined equations in GraphPad Prism version 5.0f as previously described (Lee et al., 2017). Roehrl et al. (2004) eqs. 6 and 39 were used for saturation binding, and eqs. 17 and 39 were used for competition binding. These equations are formulated in terms of the total probe, receptor, and competitor concentrations. Where applicable, the anisotropy values for the free and bound probe were constrained to be the same for multiple curves within the same experiment. In limited cases where a single competitor was assessed in an experiment and the full curve could not be obtained, the anisotropy value for the free probe (bottom of the curve) was constrained to be $>0$. No weighting was used. Fluorescence anisotropy detection used a PolarStar Omega plate reader equipped with fluorescence polarization (FP) optics and FITC filters (BMG Labtech).

cAMP Signaling Assay. COS-7 cells (American Type Culture Collection) were cultured in DMEM with $10 \%$ fetal bovine serum and incubated at $37^{\circ} \mathrm{C}$ in a humidified $5 \% \mathrm{CO}_{2}$ incubator. At $90 \%-100 \%$ confluency, cells were trypsinized, counted, and seeded in 96-well plates (Corning, Corning, NY) at 20,000 cells/well. Twenty-four hours after seeding, a plasmid encoding human RAMP1, RAMP2, or RAMP3 was cotransfected with a plasmid encoding CLR at a 1:1 ratio (125 ng/well RAMP1/2/3 and $125 \mathrm{ng} /$ well CLR) using polyethyleneimine as previously described (Bailey and Hay, 2006). Forty-eight hours after transfection, the culture medium was aspirated, and cells were incubated with cAMP assay medium [serum-free DMEM supplemented with $1 \mathrm{mM}$ IBMX and $0.1 \%(\mathrm{w} / \mathrm{v})$ fatty-acid-free BSA] for 30 minutes at $37^{\circ} \mathrm{C}$ in the presence or absence of the indicated concentration of antagonist peptide. At the 30-minute time point, the cells were stimulated with the indicated concentrations of $\mathrm{AM}(13-52)$ or $\alpha \mathrm{CGRP}(1-37)$ agonist in cAMP assay buffer in the absence or presence of antagonist at the same concentration used for the preincubation and incubated a further 30 minutes at $37^{\circ} \mathrm{C}$. The medium was then aspirated, and the cells were lysed with ice-cold $6 \%$ perchloric acid. The plate was shaken on an orbital shaker for 15 minutes at room temperature, and the lysates were neutralized by addition of potassium bicarbonate and Na-HEPES, $\mathrm{pH}$ 7.4. cAMP in the neutralized lysates was quantitated using a LANCE cAMP kit (PerkinElmer) according to the manufacturer's instructions with a 4-hour assay incubation time. LANCE TR-FRET detection used a PolarStar Omega plate reader equipped with an advanced TRF optic head and LANCE filters (BMG Labtech). The 665/620-nm emission

TABLE 1

$\mathrm{pK}_{\mathrm{I}}$ values for $\mathrm{AM}$ and CGRP variants determined by FP peptide-binding assay

\begin{tabular}{|c|c|c|c|}
\hline Peptide $^{a}$ & $\begin{array}{c}\text { MBP-RAMP1-CLR } \\
\text { ECD pK } \text { pK }_{\mathrm{I}} \pm \text { S.E.M. }(n)\end{array}$ & MBP-RAMP2- CLR ECD pK ${ }_{\mathrm{I}} \pm$ S.E.M. $(n)$ & $\begin{array}{l}\text { Selectivity, RAMP1 (R1) vs } \\
\text { RAMP2 (R2) } \Delta \log (95 \% \mathrm{CI})^{b}\end{array}$ \\
\hline $\mathrm{AM}(22-52)$ & $<4.3(2)^{c}$ & $4.63 \pm 0.10(3)$ & $\mathrm{R} 2$ \\
\hline $\mathrm{AM}(37-52)$ & $<4.3(3)$ & $4.72 \pm 0.07(3)$ & $\mathrm{R} 2$ \\
\hline Q50F & $4.97 \pm 0.07(3)$ & $5.67 \pm 0.05(3)$ & $-0.70(-0.94 \text { to }-0.46)^{* *}$ \\
\hline Q50W & $6.12 \pm 0.02(3)$ & $6.18 \pm 0.12(3)$ & $-0.06(-0.41$ to +0.28$)$ \\
\hline K46L/Q50W & $7.17 \pm 0.03(3)$ & $5.75 \pm 0.03(3)$ & $+1.42(+1.30$ to +1.54$) * * *$ \\
\hline K46L/Q50W/Y52F & $7.39 \pm 0.11(3)$ & $<4.3(3)$ & $\mathrm{R} 1$ \\
\hline S45W/Q50W & $7.40 \pm 0.05(3)$ & $7.19 \pm 0.06(3)$ & $+0.21(-0.01$ to +0.42$)$ \\
\hline S45W/K46L/Q50W & $8.14 \pm 0.10(3)$ & $6.69 \pm 0.08(3)$ & $+1.46(+1.10$ to +1.82$) * * *$ \\
\hline $\mathrm{S} 45 \mathrm{~W} / \mathrm{K} 46 \mathrm{~L} / \mathrm{Q} 50 \mathrm{~W} / \mathrm{Y} 52 \mathrm{~F}$ (AMmut) & $8.47 \pm 0.21(3)$ & $5.13 \pm 0.03(3)$ & $+3.33(+2.76 \text { to }+3.91)^{* * *}$ \\
\hline $\mathrm{S} 45 \mathrm{~W} / \mathrm{K} 46 \mathrm{M} / \mathrm{Q} 50 \mathrm{~W} / \mathrm{Y} 52 \mathrm{~F}$ & $8.10 \pm 0.16(3)$ & $5.08 \pm 0.03(3)$ & $+3.02(+2.57 \text { to }+3.47)^{* * *}$ \\
\hline CGRP(8-37) & $<4.3(3)$ & NBD $(2)$ & R1 \\
\hline CGRP(27-37) N31D/S34P/K35F (CGRPmut) & $7.48 \pm 0.12(3)$ & $<4.3(3)$ & R1 \\
\hline N31D/S34P/K35W & $8.12 \pm 0.11(3)$ & $<4.3(3)$ & R1 \\
\hline N31D/S34P/K35F/A36S & $8.24 \pm 0.04$ & $4.97 \pm 0.10$ & $+3.26(+2.95 \text { to }+3.58)^{* * *}$ \\
\hline N31D/S34P/K35W/A36S & $8.93 \pm 0.14(3)$ & $5.64 \pm 0.13(3)$ & $+3.29(+2.76 \text { to }+3.82)^{* * *}$ \\
\hline N31D/S34P/K35W/A36S/F37Y & $8.61 \pm 0.24$ & $6.33 \pm 0.11$ & $+2.28(+1.53 \text { to }+3.02)^{* *}$ \\
\hline
\end{tabular}

CI, confidence interval; NBD, no binding detected.

${ }^{a}$ All variants were in the AM(37-52) or CGRP(27-37) scaffolds.

${ }^{b}$ Statistical comparisons of RAMP1- and RAMP2-CLR ECD data were performed using unpaired Student's $t$ test.

${ }^{c}<4.3$ indicates weak binding was detected at maximum concentration used but $\mathrm{pK}_{\mathrm{I}}$ was not determined.

$* * P<0.01 ; * * * P<0.001$. 


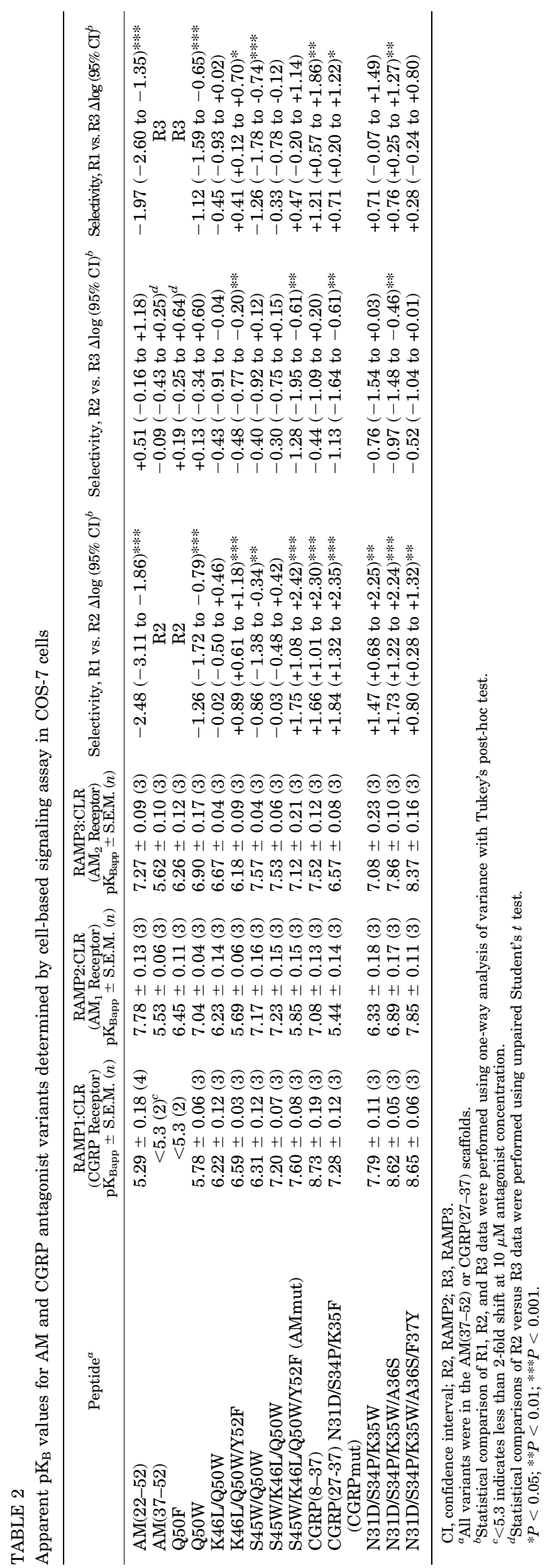

ratio was used in the data analysis, and cAMP concentration was determined by interpolation from a cAMP standard curve. Concentration-response curves were fitted by nonlinear regression in GraphPad Prism version 5.0f to the "Gaddum/Schild EC 50 shift" equation with the Schild and Hill slopes constrained to 1 to determine antagonist potency (apparent $\mathrm{pK}_{\mathrm{B}}$ ). No weighting was used. Antagonist concentrations were chosen to give a significant shift of the concentration-response curve to enable accurate determination of the apparent $\mathrm{pK}_{\mathrm{B}}$ values.

Crystallization, X-Ray Diffraction Data Collection, Structure Solution, and Refinement. Purified MBP-RAMP1.24-111$(\text { GSA })_{3}$-CLR.29-144- $\mathrm{H}_{6}$ fusion protein was mixed with synthetic $\operatorname{AM}(37-52) \mathrm{S} 45 \mathrm{~W} / \mathrm{K} 46 \mathrm{~L} / \mathrm{Q} 50 \mathrm{~W} / \mathrm{Y} 52 \mathrm{~F}$ at a 1:1.2 protein:peptide molar ratio and concentrated to $30 \mathrm{mg} / \mathrm{ml}$ as previously described (Booe et al., 2015). Crystals were grown by the hanging drop vapor diffusion method in $15 \%(\mathrm{w} / \mathrm{v})$ polyethylene glycol 3350, $0.1 \mathrm{M}$ sodium malonate ( $\mathrm{pH} 6.0$ ), $50 \mathrm{mM}$ potassium sodium tartrate, and $1 \%(\mathrm{w} / \mathrm{v})$ cadaverine. The best crystals were obtained by microseeding using a Seed Bead kit (Hampton Research). Due to their fragile nature, the crystals were cross-linked before cryoprotection by incubating the drop for 15 minutes over $25 \%$ glutaraldehyde. The cross-linked crystals were directly transferred into a cryoprotection solution comprising crystallization solution $+8 \%(\mathrm{v} / \mathrm{v})$ 2-methyl-2,4-pentanediol and flash frozen in liquid nitrogen. Diffraction data were collected remotely at LS-CAT beamline 21-ID-G $(\lambda=0.9786 \AA)$ at the Advanced Photon Source (Argonne, IL). A diffraction data set from a single crystal was processed using HKL2000 version 712 (HKL Research, Charlottesville, VA) (Otwinowski and Minor, 1997). The structure was solved by molecular replacement (MR) with Phaser version 2.6.0 (McCoy et al., 2007) using MBP with maltose removed (Protein Data Bank: 3C4M) and the RAMP1 ECD-CLR ECD heterodimer with MBP and peptide removed (Protein Data Bank: 4RWG) as search inputs. The MR solution contained four molecules of MBP and four molecules of RAMP1 ECD-CLR ECD heterodimer in the asymmetric unit. The MR solution was rigid body refined with Phenix.refine version 1.10.1-2155 (Adams et al., 2010) by treating MBP, RAMP1 ECD, and CLR ECD as rigid bodies. The model was completed by iterative rounds of manual model building using COOT (Emsley et al., 2010) and NCS and TLS restrained refinement using Phenix version 1.10.1-2155 (Adams et al., 2010). Automatic NCS restraints, stereochemistry weight optimization, and B-factor weight optimization were used.

Structural Analysis and Modeling of Peptide Variants. Structural analysis was performed in PyMOL (Schrödinger). Structural superimpositions were performed using the align command based on $\mathrm{C} \alpha$ atom positions of CLR ECD. For modeling of peptide variants, in silico mutagenesis was performed with the mutagenesis wizard.

Statistical Analysis. The binding and signaling assays were performed at least three independent times (on different days) with duplicate samples. Means from the independent replicates are reported as \pm S.E.M. Statistical comparison of $\mathrm{pK}_{\mathrm{I}}$ values from the FP assays and apparent $\mathrm{pK}_{\mathrm{B}}$ values from the signaling assays were performed in GraphPad Prism version 5.0f. Unpaired two-tailed $t$ test was used to compare the $\mathrm{pK}_{\mathrm{I}}$ values of an individual peptide variant at the RAMP1-CLR ECD and RAMP2-CLR ECD complexes. One-way analysis of variance followed by Tukey's post-hoc test was used to compare the apparent $\mathrm{pK}_{\mathrm{B}}$ values for an individual peptide variant at the three intact receptor complexes. Similarly, analysis of variance with Tukey's post-hoc test was used to compare the $\mathrm{pK}_{\mathrm{I}}$ or apparent $\mathrm{pK} \mathrm{K}_{\mathrm{B}}$ values of all $\mathrm{AM}$ or CGRP peptide variants at an individual receptor complex (e.g., RAMP1-CLR ECD or RAMP1:CLR). Significance was determined as $P<0.05, P<$ 0.01 , or $P<0.001$. All statistical comparisons are summarized in Supplemental Tables S2 and S3 and selected comparisons are shown in Tables 1 and 2 and in scatter plot format in Supplemental Figs. S4 and S7. 


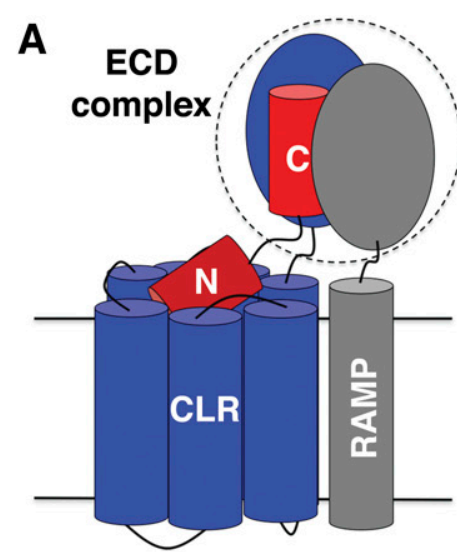

D

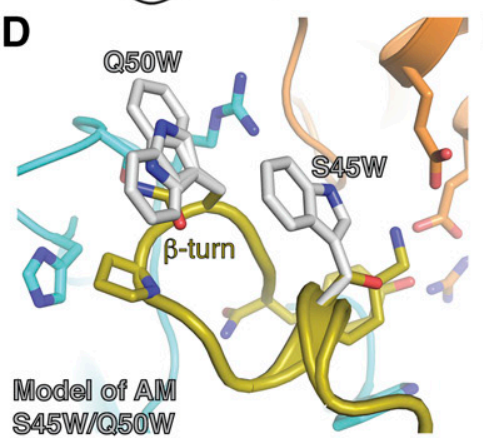

G

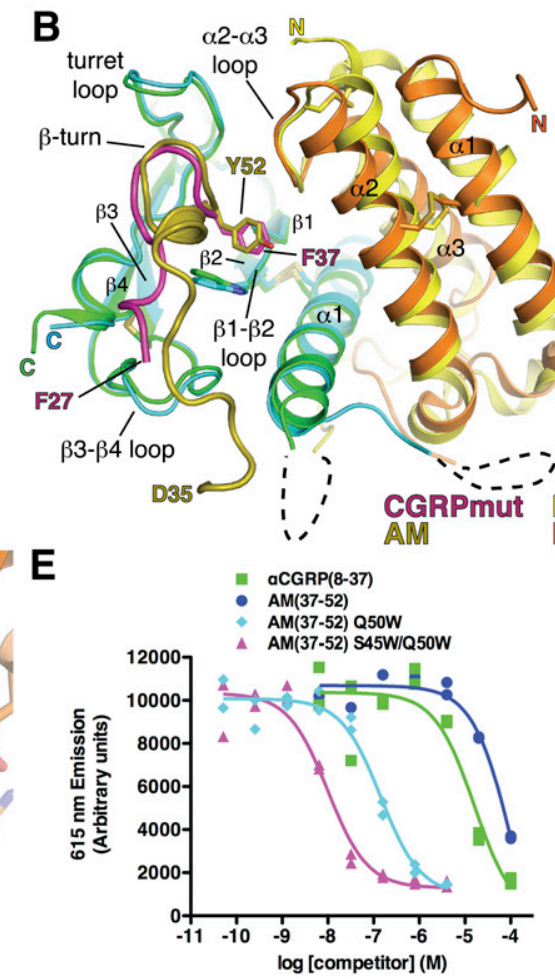

30

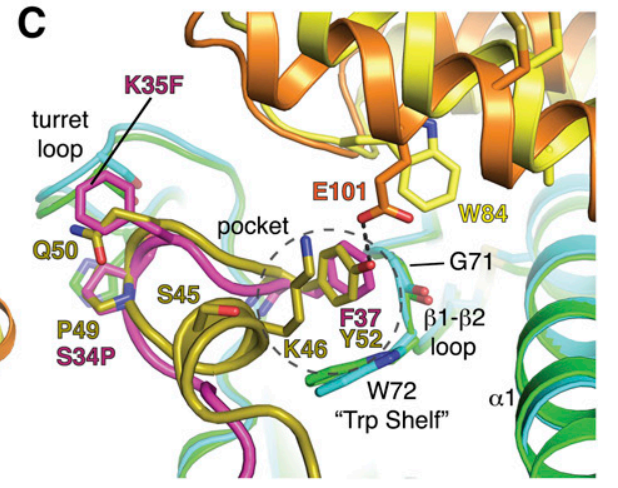

RAMPQ1 ECD-CLR ECD
RAMP2 ECD-CLR ECD

$\mathbf{F}$

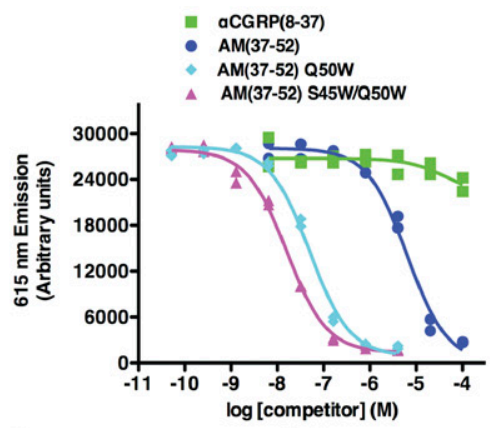

50

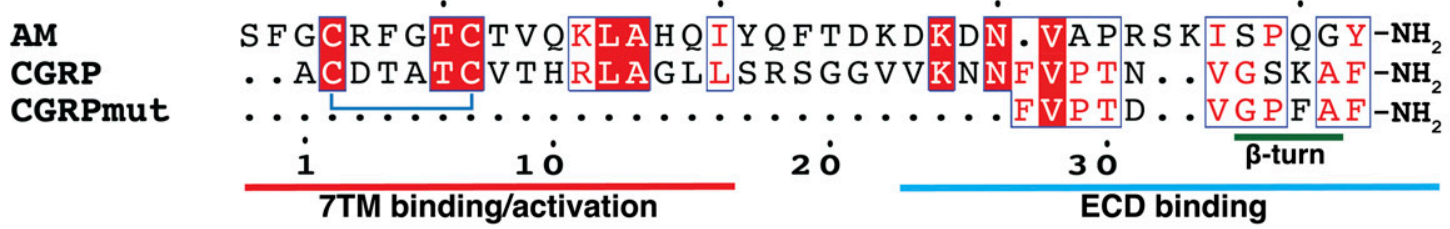

Fig. 1. Enhancing AM affinity through rational structure-based design. (A) “Two-domain” peptide-binding model for RAMP:CLR complexes. (B) Crystal structures of AM-bound MBP-RAMP2-CLR ECD (Protein Data Bank 4RWF) and CGRPmut-bound MBP-RAMP1-CLR ECD (PDB 4RWG) in cartoon representation. MBP is omitted for clarity. Dotted lines represent disordered linkers connecting the ECDs. (C) Detailed view centered on the pocket occupied by the C-terminal AM Y52 and CGRPmut F37. (D) Model of AM S45W/Q50W bound to RAMP2-CLR ECD. Two conformations are modeled for Q50W. (E and F) Competition AlphaLISA peptide-binding assays with purified MBP-RAMP1-(GS) $5_{5}$-CLR ECD (E) or MBP-RAMP2[L160R]-(GS) $)_{5}$-CLR ECD fusion proteins $(\mathrm{F})$ and indicated competitor peptides. Each panel is representative of two to three independent experiments performed in duplicate. Individual data points for each technical replicate are shown. (G) Amino acid sequence alignment of human AM(13-52), $\alpha$ CGRP(1-37), and CGRPmut. Numbers above the sequences correspond to AM amino acid position, whereas numbers below the sequences correspond to CGRP amino acid position. Dark-blue line represents the N-terminal disulfide linkage.

\section{Results}

Rational Design of Short High-Affinity AM and CGRP Antagonist Variants. The two-domain agonist-binding mechanism enables $\mathrm{N}$-terminal peptide truncation to be used to create competitive antagonists such as the traditional AM (22-52) and CGRP(8-37) antagonists that have nanomolar affinity for their receptors (Fig. 1, A and G). Unfortunately, further truncation to the ECD-binding regions, $\operatorname{AM}(37-52)$ and CGRP(27-37), weakens affinity into the micromolar range (Moad and Pioszak, 2013). We first set out to develop high-affinity $\mathrm{AM}(37-52)$ and $\mathrm{CGRP}(27-37)$ variants because we reasoned that these would serve as ideal scaffolds in which to add additional amino acid substitutions designed to probe RAMP allosteric effects and direct peptide contacts.

In our crystal structures of peptide-bound tethered MBPRAMP1/2 ECD-CLR ECD fusion proteins, we used C-terminal antagonist fragments of a high-affinity CGRP N31D/S34P/K35F variant, which we termed CGRPmut for simplicity, and AM (Fig. 1, B and C) (Booe et al., 2015). The three CGRPmut substitutions were originally identified through systematic mutagenesis (Rist et al., 1998). The structures revealed that CGRPmut S34P promotes a key $\beta$-turn structure, and K35F contacts the CLR "turret loop" to enhance affinity (Fig. 1C). Given the shared peptide $\beta$-turn structures, we reasoned that Phe substitution at AM Q50, which is equivalent to CGRP K35 (Fig. 1G), should enhance its affinity. Using in silico mutagenesis in PyMOL, we modeled Q50F and substitutions at several positions in AM. We predicted that a Trp at position 50 could adopt either of two conformations to enhance affinity by contacting the turret loop, and that an additional Trp at position 45 in the helical turn would permit stacking of the Trp residues to stabilize the $\beta$-turn (Fig. 1D). In the context of AM(37-52), we measured the effects of the Q50F, Q50W, and S45W/Q50W substitutions on binding to the purified tethered fusion proteins using an AlphaLISA luminescent proximity peptide-binding assay similar to those previously described (Moad and Pioszak, 2013; Lee et al., 2016). In a competition binding format, the Q50F substitution enhanced affinity 10-fold for both tethered RAMP1-CLR ECD and RAMP2-CLR ECD (data not shown), whereas Q50W enhanced 

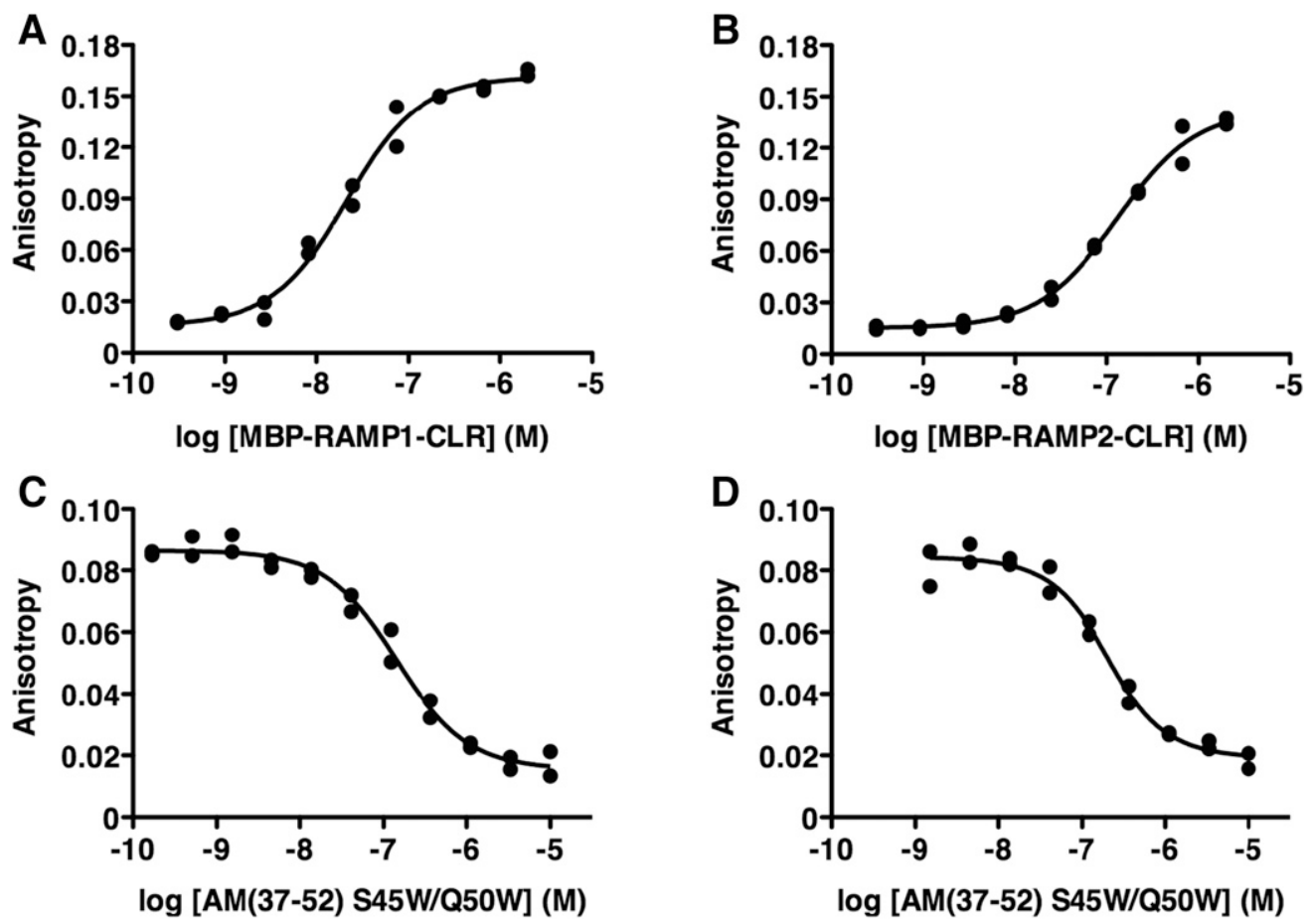

Fig. 2. FP peptide-binding assay utilizing an AM(37-52) S45W/Q50W probe. (A and B) Saturation binding assays with $7 \mathrm{nM}$ FITC-AM(37-52) S45W/Q50W and indicated concentrations of purified MBP-RAMP1-(GS) 5 -CLR ECD (A) or MBP-RAMP2[L106R]-(GS) $)_{5}$-CLR ECD (B) tethered fusion proteins. (C and D) Competition binding assays using $7 \mathrm{nM}$ FITC-AM(37-52) S45W/Q50W and $15 \mathrm{nM}$ MBP-RAMP1-(GS) $)_{5}$-CLR ECD (C) or 110 nM MBPRAMP2[L106R]-(GS) $)_{5}$-CLR ECD complexes (D) and indicated concentration of unlabeled competitor AM(37-52) S45W/Q50W. Each panel is representative of at least three independent experiments performed in duplicate. Individual data points for each technical replicate are shown.

affinity $\sim 100$-fold for both proteins (Fig. 1, E and F). The inclusion of S45W with Q50W further enhanced affinity such that the double mutant bound both tethered ECD complexes with $\mathrm{IC}_{50}$ values in the mid nanomolar range (Fig. 1, E and F).
The competition AlphaLISA assay is ill suited for determining accurate equilibrium constants, so we developed a fluorescence polarization/anisotropy peptide-binding assay similar to one we recently reported for the calcitonin receptor

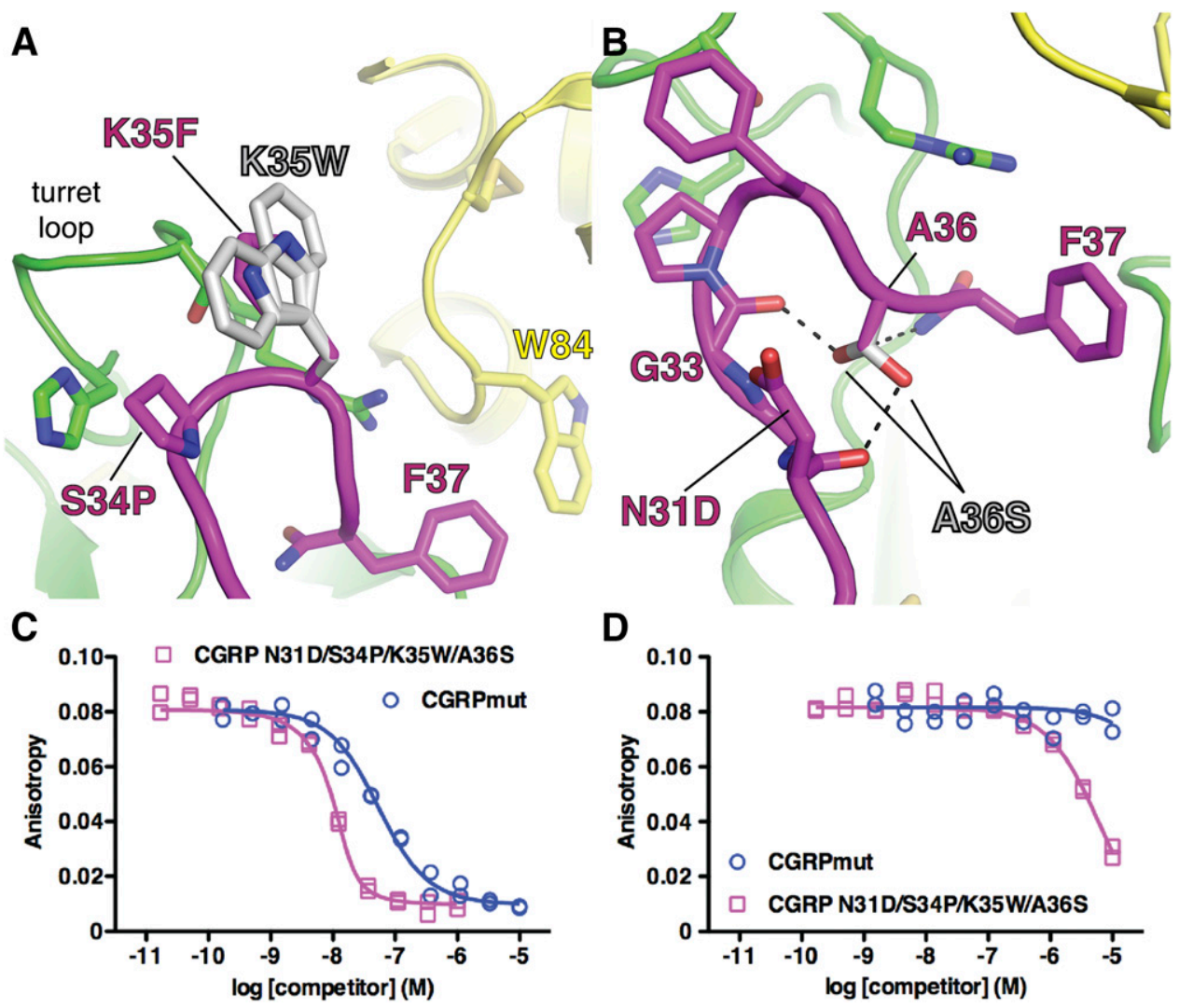

Fig. 3. Enhancing CGRP peptide affinity through rational structure-based design. (A) Modeled CGRP K35W showing two possible conformations. (B) Modeled CGRP A36S showing hydrogen bonds in two possible conformations. (C and D) Representative competition binding FP assays using 7 nM FITC-AM(37-52) S45W/Q50W and $15 \mathrm{nM}$ MBP-RAMP1-(GS) $)_{5}$ CLR ECD (C) or $110 \mathrm{nM}$ MBP-RAMP2[L106R]-(GS) $5_{5}$ CLR ECD (D) with competitor peptides CGRPmut or CGRP(27-37) N31D/S34P/ K35W/A36S. Each panel is representative of at least three independent experiments performed in duplicate. Individual data points for each technical replicate are shown. 


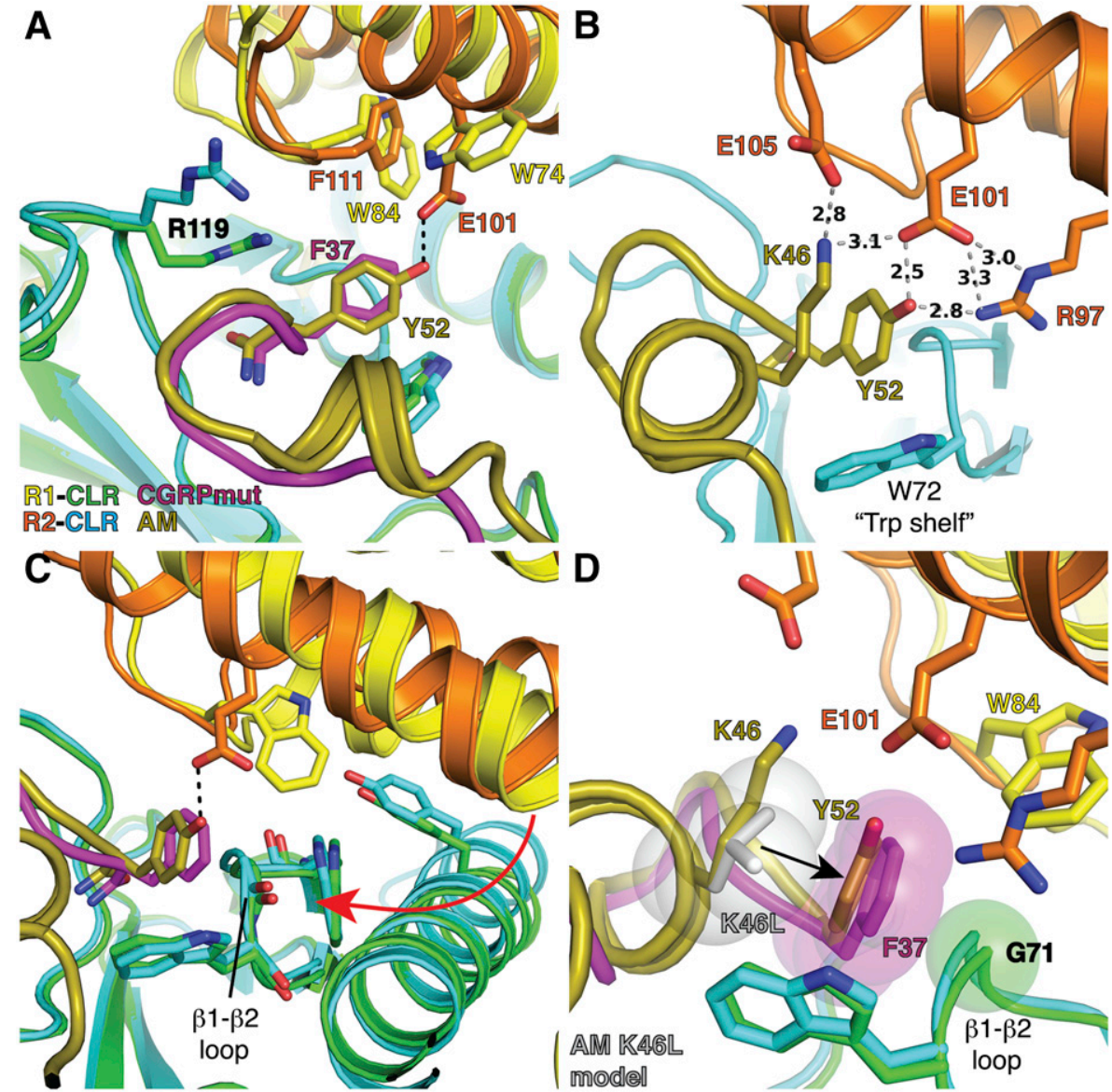

Fig. 4. Designing peptide substitutions to exploit RAMP-peptide contacts and putative RAMP allosteric modulation of CLR ECD conformation. (A) Detailed view of AM and CGRPmut C-terminal residue contacts with the RAMP subunits (Protein Data Bank 4RWF and 4RWG). Dotted line represents a hydrogen bond. (B) Hydrogen bond network involving AM K46, Y52, and RAMP2 R97, E101, and E105 (Protein Data Bank 4RWF). Hydrogen bond distances in angstroms are in black text. (C) Differences in the CLR $\beta 1-\beta 2$ loop position in the RAMP1- and RAMP2-CLR ECD complexes (Protein Data Bank 4RWF and 4RWG). The red arrow indicates the putative allosteric pathway propagating changes from the RAMP:CLR interface to the CLR $\beta 1-\beta 2$ loop (see also Supplemental Movie S1). (D) Modeling AM K46L suggests that it would push Y52 to a position similar to that of CGRPmut F37, allowing contact with G71 in RAMP1-CLR while clashing with G71 in RAMP2-CLR Semitransparent space-filling spheres are shown for the modeled Leu at AM position 46, CGRPmut F37, and G71 in RAMP1-CLR ECD.
ECD (Lee et al., 2017) to enable a more thorough quantitative analysis of the binding of AM and CGRP variants to the purified tethered RAMP1/2-CLR ECD complexes (Supplemental Fig. S1A). As a probe, we used AM(37-52) S45W/Q50W labeled at the $\mathrm{N}$ terminus with FITC. The label had no effect on ECD-binding affinity (Supplemental Fig. S1, B and C). A robust, saturable anisotropy signal was observed upon titration of a fixed probe concentration with MBP-RAMP1-CLR ECD, but not with an unrelated MBP-RSPO fusion protein, and nonspecific binding was negligible (Supplemental Fig. S1, D and E). The FITC-AM(37-52) S45W/Q50W probe exhibited a $\mathrm{pK}_{\mathrm{D}}$ of $7.72 \pm 0.12$ for MBP-RAMP1-CLR ECD and $\mathrm{a} \mathrm{pK}_{\mathrm{D}}$ of $6.83 \pm 0.04$ for MBP-RAMP2-CLR ECD (Fig. $2, \mathrm{~A}$ and B). In a competition binding assay format, unlabeled $\mathrm{AM}(37-52)$ S45W/Q50W exhibited a $\mathrm{pK}_{\mathrm{I}}$ of $7.40 \pm 0.05$ for MBPRAMP1-CLR ECD and a $\mathrm{pK}_{\mathrm{I}}$ of $7.19 \pm 0.06$ for MBPRAMP2-CLR ECD (Fig. 2, C and D; Table 1). In the competition assay, the affinity of $\mathrm{AM}(37-52)$ for both the tethered CGRP and $\mathrm{AM}_{1}$ receptor ECD complexes was increased by the rationally designed substitutions with a rank order of affinity-enhancement of S45W/Q50W > Q50W > Q50F (Table 1). Notably, the double mutant dramatically increased affinity from the mid- to highmicromolar range into the mid-nanomolar range.

Modeling predicted that a Trp at CGRP position 35 could adopt either of two conformations to contact the turret loop and possibly confer higher affinity than the K35F substitution in CGRPmut (Fig. 3A). We further predicted that Ser at position 36 could adopt either of two conformations in which its side chain hydrogen bonds with either the main chain carbonyl of D31 or the main chain G33 carbonyl and the C-terminal amide to stabilize the $\beta$-turn (Fig. 3B). In the FP assay, CGRPmut bound RAMP1-CLR ECD with a $\mathrm{pK}_{\mathrm{I}}$ of $7.48 \pm 0.12\left(\mathrm{~K}_{\mathrm{I}} \sim 33 \mathrm{nM}\right)$ in good agreement with the $\sim 30 \mathrm{nM}$ $\mathrm{IC}_{50}$ value reported for its binding to the intact CGRP receptor in SK-N-MC cell membranes (Rist et al., 1998) (Fig. 3C; Supplemental Fig. S2B; Table 1). Replacing K35F in CGRPmut with K35W increased affinity for RAMP1-CLR ECD by $\sim 4.5$-fold $\left(\mathrm{pK}_{\mathrm{I}}=8.12 \pm 0.11\right.$ ), and adding A36S into CGRPmut increased affinity $\sim 6$-fold $\left(\mathrm{pK}_{\mathrm{I}}=8.24 \pm 0.04\right)$ (Supplemental Fig. S2B; Supplemental Table S2; Table 1). Combining these two substitutions yielded the CGRP(27-37) N31D/S34P/K35W/A36S variant with 28-fold improved affinity for RAMP1-CLR ECD $\left(\mathrm{pK}_{\mathrm{I}}=8.93 \pm 0.14\right)$ over that of CGRPmut and an approximately 1700-fold weaker affinity for RAMP2-CLR ECD $\left(\mathrm{pK}_{\mathrm{I}}=5.64 \pm 0.13\right)$ (Fig. 3, C and D; Supplemental Table S2; Table 1).

Probing the Role of RAMP Allosteric Effects and RAMP-Peptide Contacts in Ligand Selectivity through AM and CGRP Variants. AM Y52 and CGRP F37 are critical for receptor binding (Moad and Pioszak, 2013; Watkins et al., 2013), but their role in selectivity is less clear. CGRPmut F37 contacts RAMP1 W84 and AM Y52 hydrogen bonds with RAMP2 E101, whereas RAMP2 F111 cannot make the CGRP F37 contact and RAMP1 W74 cannot hydrogen 

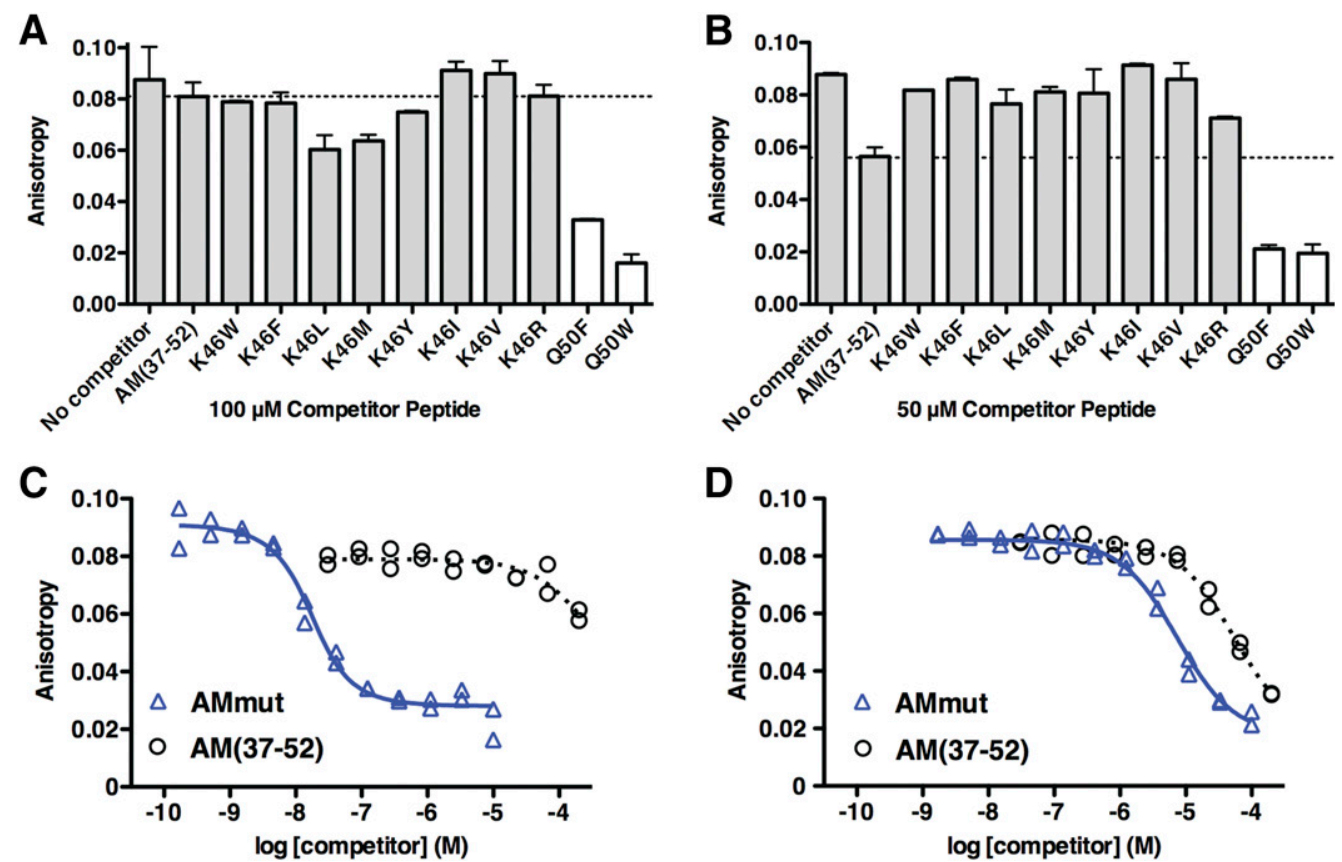

Fig. 5. Binding of AM variants substituted at position 46 and the AMmut quadruple mutant to purified MBP-RAMP1/2-CLR ECD complexes. (A and B) Single-point competition FP assays using $7 \mathrm{nM}$ FITC-AM S45W/Q50W and $15 \mathrm{nM}$ MBP-RAMP1-(GS) $)_{5}$ CLR ECD (A) or $110 \mathrm{nM}$ MBP-RAMP2[L106R]$(\mathrm{GS})_{5}$-CLR ECD (B) with indicated concentration of competitor peptides. Each of the variants is in the AM(37-52) scaffold. (C and D) Competition binding FP assays using 7 nM FITC-AM(37-52) S45W/Q50W and 15 nM MBP-RAMP1-(GS) 5 -CLR ECD (C) or 110 nM MBP-RAMP2[L106R]-(GS) 5 -CLR ECD (D) with competitor peptides $\mathrm{AM}(37-52)$ and the $\mathrm{S} 45 \mathrm{~W} / \mathrm{K} 46 \mathrm{~L} / \mathrm{Q} 50 \mathrm{~W} / \mathrm{Y} 52 \mathrm{~F}$ variant (AMmut). (A) and (B) are representative of at least two independent experiments performed in duplicate with error bars shown as S.D., and (C) and (D) are representative of three independent experiments performed in duplicate with individual data points for each technical replicate shown.

bond with AM Y52, suggesting that distinct RAMP-peptide contacts contribute to selectivity (Fig. 4A). CGRPmut F37 is the only residue that contacts RAMP1, but AM binding is more complex because, in addition to Y52, K46 also contacts RAMP2 (Fig. 4B). Despite the apparent hydrogen bond network involving AM K46 and Y52 and RAMP2 R97, E101, and E105, only mutation of RAMP2 E101 impaired $\mathrm{AM}_{1}$ function in a signaling assay; the RAMP2 R97A and E105A mutants retained wild-type response to AM (Booe et al., 2015). The primary role of AM K46 appears to be to pack against Y52 and the CLR Trp shelf(Fig. 4B), and thus, only the AM C-terminal residue makes a contact of importance to the RAMP subunit. Given the paucity of direct RAMP-peptide contacts, we reasoned that RAMP alteration of CLR conformation might also contribute to selectivity.

RAMP-mediated conformational changes in the CLR ECD were visualized by comparing the CGRPmut-bound RAMP1CLR ECD and AM-bound RAMP2-CLR ECD structures in a molecular morph (Supplemental Movie S1). The morph highlights three areas of CLR change that appear to be RAMPdependent. The first involves different conformations of CLR R119 on the turret loop adjacent to the RAMP $\alpha 2-\alpha 3$ loop. The second involves a subtle shift in the $\beta 1-\beta 2$ loop that appears to be a change propagated from the RAMP:CLR interface to the loop (Fig. 4C; Supplemental Movie S1). The third involves the $\mathrm{N}$ terminus of CLR $\alpha 1$, which is "unwound" in the RAMP2CLR structure. We reasoned the CLR R119 change is not a significant selectivity determinant because the apparently RAMP1-induced "down" position of R119 would seem to sterically disfavor AM binding, but our aforementioned results indicated that AM variants can bind RAMP1-CLR ECD with high affinity. We also disregarded the change in the CLR $\alpha 1 \mathrm{~N}$ terminus as it may be an artifact of tethering it to the RAMP ECD $\mathrm{C}$ terminus. We therefore focused on the subtle shift in the CLR $\beta 1-\beta 2$ loop, with the idea that it would alter the shape of the pocket occupied by the peptide C-terminal residue. Notably, this $\beta 1-\beta 2$ loop shift was also evident in ligand-free RAMP1:CLR and RAMP2:CLR ECD crystal structures (ter Haar et al., 2010; Kusano et al., 2012) (Supplemental Fig. S3).

Fortunately, the unique helical turn in AM appeared to provide an avenue to probe the putative allosteric effect. Using in silico mutagenesis, we predicted that a Leu at AM position 46 would push the AM Y52 side chain to adopt a position similar to that of CGRPmut F37 to favor RAMP1-CLR ECD binding due to better complementarity with the pocket while sterically disfavoring RAMP2-CLR ECD binding, because the altered Y52 position would clash with G71 in the $\beta 1-\beta 2$ loop (Fig. 4D). AM(37-52) peptides bearing K46 substitution with Leu or other hydrophobic amino acids were tested for binding to MBP-RAMP1- and RAMP2-CLR ECD proteins in a singlepoint competition FP assay (Fig. 5, A and B). We also tested $\mathrm{K} 46 \mathrm{R}$ to see if introduction of an Arg would enable ionic interaction with RAMP2 E101 and/or E105. The AM K46L and K46M variants appeared to have enhanced affinity for RAMP1-CLR ECD (Fig. 5A), whereas all of the K46 variants had decreased binding to RAMP2-CLR ECD (Fig. 5B). Combining K46L with the affinity-enhancing Q50W or S45W/Q50W yielded variants that were 26- to 29-fold selective for RAMP1-CLR ECD over RAMP2-CLR ECD, with the triple mutant exhibiting affinity for RAMP1-CLR ECD in the low-nanomolar range $\left(\mathrm{pK}_{\mathrm{I}}=8.14 \pm 0.10\right)$ (Supplemental 


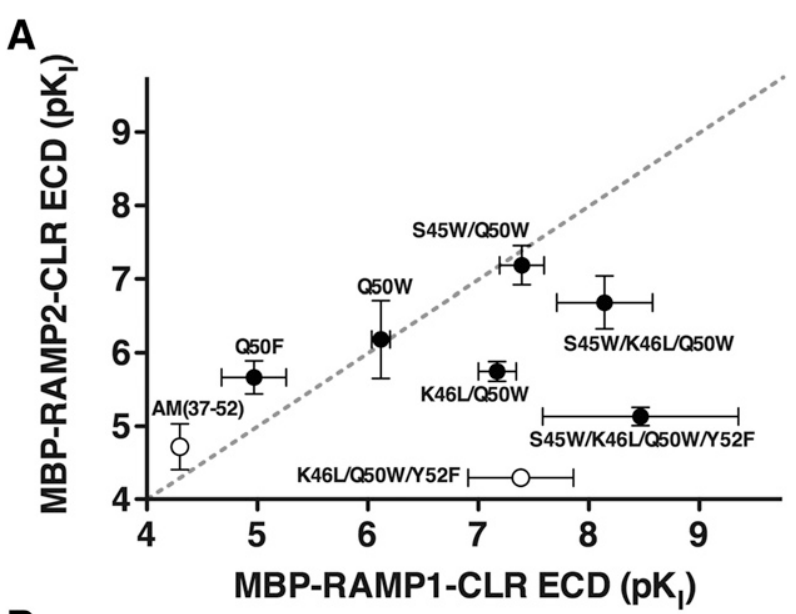

B

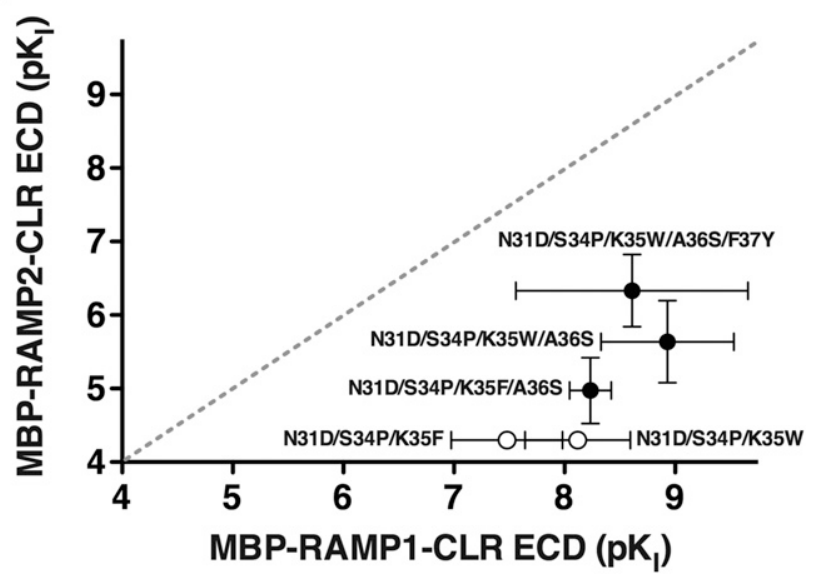

Fig. 6. Summary of $A M$ and CGRP $p K_{I}$ values obtained in the FP assay with purified $E C D$ complexes. Plot of the mean $p K_{I}$ values for $A M$ variants (A) or CGRP variants (B) at either MBP-RAMP1-CLR ECD or MBPRAMP2-CLR ECD purified fusion proteins. AM variants are in the context of AM(37-52), whereas CGRP variants are in the context of CGRP(27-37). Open circles indicate that $\mathrm{pK}_{\mathrm{I}}$ values were only obtainable at one of the purified RAMP1/2-CLR ECD complexes, whereas binding the other receptor had an estimated $\mathrm{pK}_{\mathrm{I}}$ of $<4.3$. Error bars indicate $95 \%$ confidence intervals. See Supplemental Fig. S4, Supplemental Table S2, and Table 1 for statistical analysis.

Fig. S2A; Table 1). The FP peptide-binding data for all peptide variants at purified ECD complexes are summarized in $\mathrm{pK}_{\mathrm{I}}$ correlation plots (Fig. 6), and representative competition binding curves are shown in Supplemental Fig. S2. Statistical analysis is presented in table (Supplemental Table S2; Table 1) and scatter plot (Supplemental Fig. S4) formats.

Next, we examined C-terminal residue swaps in the highaffinity AM and CGRP variants to probe the role of direct RAMP-peptide contacts in selectivity. Inclusion of Y52F with $\mathrm{K} 46 \mathrm{~L} / \mathrm{Q} 50 \mathrm{~W}, \mathrm{~S} 45 \mathrm{~W} / \mathrm{K} 46 \mathrm{~L} / \mathrm{Q} 50 \mathrm{~W}$, or $\mathrm{S} 45 \mathrm{~W} / \mathrm{K} 46 \mathrm{M} / \mathrm{Q} 50 \mathrm{~W}$ in AM dramatically decreased affinity to RAMP2-CLR ECD and thereby enhanced selectivity for RAMP1-CLR ECD (Fig. 6A; Supplemental Figs. S2A and S4A; Table 1). The $\mathrm{AM}(37-52) \mathrm{S} 45 \mathrm{~W} / \mathrm{K} 46 \mathrm{~L} / \mathrm{Q} 50 \mathrm{~W} / Y 52 \mathrm{~F}$ quadruple mutant, hereafter designated AMmut, exhibited strong nanomolar affinity for RAMP1-CLR ECD $\left(\mathrm{pK}_{\mathrm{I}}=8.47 \pm 0.21\right)$ and $>2000$-fold weaker micromolar affinity for RAMP2-CLR ECD $\left(\mathrm{pK}_{\mathrm{I}}=5.13\right.$ \pm 0.03) (Fig. 5, C and D; Table 1). Addition of F37Y into CGRP N31D/S34P/K35W/A36S had no significant effect on its affinity for RAMP1-CLR ECD, but enhanced affinity $\sim 5$-fold for
RAMP2-CLR ECD $\left(\mathrm{pK}_{\mathrm{I}}=6.33 \pm 0.11\right)$ (Fig. 6B; Supplemental Fig. S2B and S4B; Table 1).

Antagonism of AM and CGRP Variants at FullLength Receptors in Cells. The abilities of selected AM and CGRP variants to antagonize cAMP signaling at the three RAMP:CLR complexes transiently expressed in COS-7 cells was assessed to extend our results to the full-length receptors in a natural cell membrane environment. Importantly, this cell-based assay also allowed us to determine the potency of the variants at the $\mathrm{AM}_{2}$ receptor, for which we lack the corresponding purified RAMP3-CLR ECD complex due to difficulties with its expression and purification. Antagonist apparent $\mathrm{pK}_{\mathrm{B}}$ values were determined from the dextral displacement of the agonist concentration-response curves resulting from a fixed concentration of the variants. Representative data for AMmut and CGRP(27-37) N31D/S34P/K35W/A36S antagonism at each receptor are shown in Fig. 7, A and B, and representative data for the other AM and CGRP variants are shown in Supplemental Figs. S5 and S6, respectively. The apparent $\mathrm{pK}_{\mathrm{B}}$ values and the receptor selectivity of each $\mathrm{AM}$ and CGRP variant are listed in Table 2, and these data are summarized in apparent $\mathrm{pK}_{\mathrm{B}}$ heat maps (Fig. 8). Statistical analysis is shown in table (Table 2; Supplemental Table S3) and scatter plot (Supplemental Fig. S7) formats.

The Q50F and Q50W substitutions enhanced the antagonist potency of $\mathrm{AM}(37-52)$; however, these variants displayed selectivity for the AM receptors over the CGRP receptor ( 15-fold for Q50W) that was not observed in the ECDbinding assay (Fig. 8A; Table 2). Combining K46L with Q50W increased potency for the CGRP receptor and decreased potency at the $\mathrm{AM}_{1}$ receptor such that the K46L/Q50W double mutant was relatively nonselective with high-nanomolar range potency. Including the C-terminal Y52F swap in $\mathrm{K} 46 \mathrm{~L} / \mathrm{Q} 50 \mathrm{~W} / \mathrm{Y} 52 \mathrm{~F}$ appeared to further decrease potency at the $\mathrm{AM}_{1}$ receptor and increase potency at the CGRP receptor. Although these potency changes due to Y52F did not reach statistical significance (Supplemental Fig. S7A; Supplemental Table S3), the trends were consistent with a C-terminal Phe favoring RAMP1 and disfavoring RAMP2. The S45W/Q50W double mutant had increased potency at all three receptors, but again, in contrast to the ECD-binding data, this variant was selective for the AM receptors over the CGRP receptor. Adding K46L to S45W/Q50W increased potency for the CGRP receptor such that the $\mathrm{S} 45 \mathrm{~W} / \mathrm{K} 46 \mathrm{~L} / \mathrm{Q} 50 \mathrm{~W}$ triple mutant was nonselective with mid-nanomolar range potency. Last, addition of Y52F to yield AMmut significantly reduced potency at the $\mathrm{AM}_{1}$ receptor. AMmut thus had a dramatically altered receptor-binding profile as compared with the $\mathrm{AM}(37-52)$ parent such that it exhibited strong nanomolar potency at the CGRP $\left(\mathrm{pK}_{\mathrm{Bapp}}=7.60 \pm 0.08\right)$ and $\mathrm{AM}_{2}$ receptors $\left(\mathrm{pK}_{\mathrm{Bapp}}\right.$ $=7.12 \pm 0.21$ ) with 56 -fold selectivity for CGRP over $\mathrm{AM}_{1}$ and $\sim 19$-fold selectivity for $\mathrm{AM}_{2}$ over $\mathrm{AM}_{1}$ (Fig. 8A; Supplemental Fig. S7A; Table 2).

Replacing K35F in CGRPmut with K35W increased potency at all three receptors $\sim 3$ - to 8-fold while not substantially altering selectivity (Fig. 8B; Supplemental Fig. S7B; Table 2). Inclusion of A36S increased potency for each receptor an additional $\sim 4$ - to 6-fold such that the quadruple N31D/S34P/K35W/A36S variant had strong low-nanomolar range potency for the CGRP receptor $\left(\mathrm{pK}_{\mathrm{Bapp}}=8.62 \pm 0.05\right)$ with a selectivity profile similar to that of the CGRPmut 


\section{RAMP1:CLR (CGRP receptor)}

A
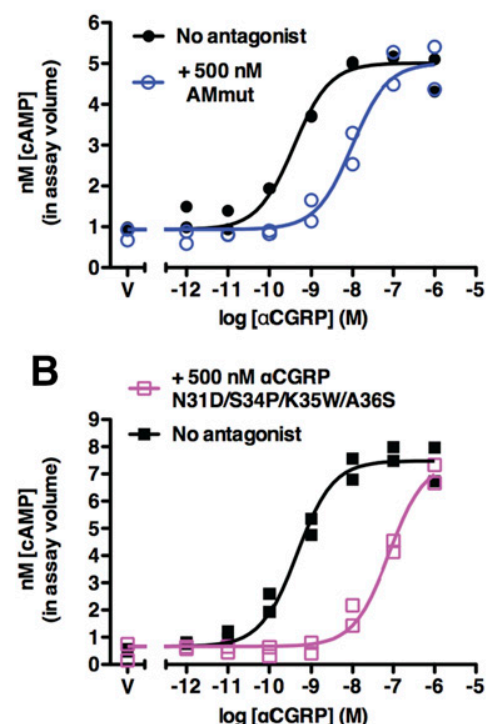
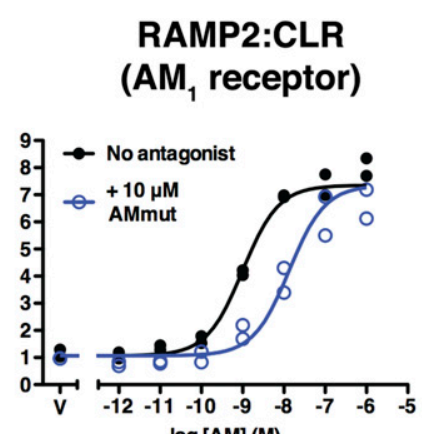

$\log$ [AM] (M)

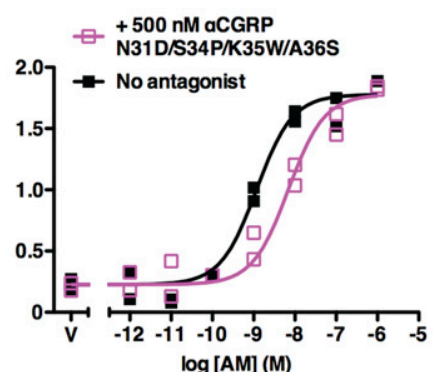

RAMP3:CLR (AM ${ }_{2}$ receptor)
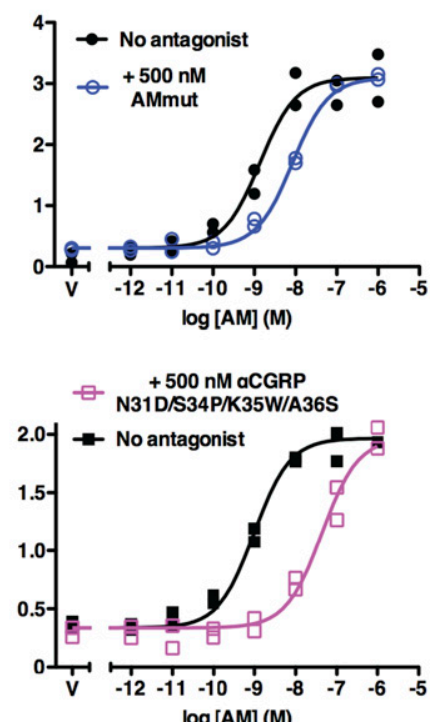

Fig. 7. Antagonism of $A M$ and CGRP variants at intact RAMP:CLR complexes in COS-7 cells. Concentration-response curves for CGRP, $\mathrm{AM}_{1}$, and $\mathrm{AM}_{2}$ receptors transiently expressed in COS-7 cells stimulated with $\alpha$ CGRP (CGRP receptor) or AM (AM receptors) agonists in the presence or absence of the indicated concentrations of AMmut (A) or CGRP(27-37) N31D/S34P/K35W/A36S (B). V, represents vehicle control with no agonist. Each panel is representative of three independent experiments performed in duplicate. Individual data points for each technical replicate are shown.

parent (54-fold selectivity for CGRP over $\mathrm{AM}_{1}$ and $\sim 9$-fold selectivity for $\mathrm{AM}_{2}$ over $\left.\mathrm{AM}_{1}\right)$. Notably, CGRP(27-37) N31D/S34P/K35W/A36S was comparable in activity to the much longer traditional CGRP(8-37) antagonist. Last, adding the F37Y C-terminal residue swap had no effect on potency at the CGRP receptor, but increased potency at the $\mathrm{AM}_{1}$ receptor. The N31D/S34P/K35W/A36S/F37Y variant thus exhibited strong nanomolar potency for all three receptors with a reduced ability to discriminate $\mathrm{CGRP}$ and $\mathrm{AM}_{1}$, although it still preferred the CGRP receptor over $\mathrm{AM}_{1}$ (Fig. 8B; Supplemental Fig. S7B; Table 2).

Structural Basis of Enhanced Affinity and Altered Selectivity of AMmut for the CGRP Receptor. To see if the AM substitutions functioned as designed, we crystallized MBP-RAMP1-CLR ECD with bound AMmut (Supplemental Fig. S8A) and determined the structure at a resolution of $2.80 \AA$ (Supplemental Table S4). Electron density was observed for the peptide in each of the four molecules present in the asymmetric unit, but the density for the ECD complex and peptide in Mol 4 (protein chain D:peptide chain $\mathrm{H}$ ) was particularly poor, so we ignored this complex in our analysis. The best density and lowest B-factors were observed for Mol 2 (protein chain B:peptide chain F) and Mol 3 (protein chain C: peptide chain G) (Supplemental Fig. S8B; Supplemental Table S4). We largely focused on Mol 2 because, although AMmut in Mol 3 was the most well ordered, the MBP in this molecule is shifted closer to the peptide as compared with the other molecules, such that it packs against AMmut S45W, and we therefore cannot rule out an effect of $\mathrm{MBP}$ on the conformation of this residue (Supplemental Fig. S8, C and D).

AMmut occupies RAMP1-CLR ECD with the same mainchain conformation observed for AM bound to RAMP2-CLR ECD (Fig. 9, A and B). The Trp at position 50 adopts the rotamer in which the benzene ring of the indole contacts $\mathrm{AM}$ $\mathrm{P} 49$, thus presumably stabilizing the peptide $\beta$-turn in addition to making contact with the CLR turret loop as designed. The conformation of the Trp at position 45 was not unambiguously defined except in Mol 3, where MBP may have constrained its position. In Mol 3 (peptide chain G), Trp45 stacked against Trp50 (Supplemental Fig. S8D). In Mol 1 and Mol 2, the density for the Trp45 side chain suggested alternative conformations, and we modeled two such conformations in Mol 2 (peptide chain F) that involve the indole contacting either Trp50 or the introduced Leu at position 46 (Fig. 9A; Supplemental Fig. S8D). Leu46 packed against the phenyl ring of the Phe introduced at position 52 and pushed it to a position similar to that of CGRPmut F37 as designed (Fig. 9, C and D). RAMP1-CLR ECD with bound AMmut exhibited the same $\beta 1-\beta 2$ loop position observed with bound CGRPmut. CLR R119 adopted the "down" conformation presumably induced by RAMP1, but its position was slightly shifted to accommodate the difference in the AM $\beta$-turn position as compared with that of CGRPmut (Fig. 9C). Last, the CLR Trp shelf and $\beta 3-\beta 4$ loop adopted conformations similar to those observed in AM-bound RAMP2-CLR ECD, presumably because these changes are peptide-dependent rather than RAMP-dependent (Fig. 9, B and C).

\section{Discussion}

AM and CGRP signaling is complex because they activate three similar heterodimeric RAMP:CLR complexes. Crystal structures of the CGRPmut- and AM-bound tethered RAMP1-CLR and RAMP2-CLR ECD complexes, respectively, revealed that the peptides share a common binding site on CLR and make only a single contact of importance with the RAMP subunits (Booe et al., 2015). We posited that the RAMP subunits determine peptide selectivity through a combination of their distinct contacts with the AM/CGRP C-terminal residue and their modulation of CLR conformation, i.e., 
allosteric effects. Here, we explored this hypothesis through the use of rationally designed AM and CGRP antagonist variants. Our purpose was 3-fold: 1) develop short highaffinity AM and CGRP variants, 2) probe the contributions of RAMP allosteric effects and direct peptide contacts to ligand selectivity, and 3) inform efforts to develop novel potent and selective AM/CGRP-based pharmacological tools and therapeutics.

Through structure-guided design targeting AM positions 45 and 50 and CGRP positions 35 and 36, we increased the affinity of the minimal C-terminal antagonist fragment of AM from the micromolar into the nanomolar range and further increased the affinity of CGRPmut (Rist et al., 1998) approximately 20 -fold. Our results are consistent with the idea that stabilizing the AM/CGRP $\beta$-turn in the receptor-bound conformation increases affinity. Indeed, exploiting turn structures is an established strategy in engineering peptide ligands for G protein-coupled receptors (Gruber et al., 2010). The AM Q50W substitution enhanced affinity more than Q50F, which presumably contacts the CLR turret loop similar to CGRPmut F35. The crystal structure of AMmut-bound RAMP1-CLR ECD revealed that the Trp50 indole contacts the CLR turret loop, but it also packs against AM P49 (Fig. 9). We predict that this intramolecular interaction stabilizes the $\beta$-turn and is largely responsible for the potent effect of this substitution. Addition of a Trp at position 45 presumably further stabilizes the receptor-bound conformation by stacking against Trp50 and/or Leu46 in AMmut. Trp at position 35 in CGRP enhanced affinity more than $\mathrm{K} 35 \mathrm{~F}$ in CGRPmut, and we suspect that the Trp indole packs against Pro at CGRP position 34. The CGRP A36S substitution also appears to enhance affinity by stabilizing the $\beta$-turn, probably via hydrogen bonds with the G33 carbonyl and the C-terminal amide (Fig. 3B). It is unclear if these putative $\beta$-turn-stabilizing effects occur in the free peptides or only when receptor-bound. Interestingly, evolution has yielded "substitutions" in other species similar to some of those found here at AM position 50 and CGRP position 36 (Supplemental Fig. S9, A and B). Zebrafish AM has a Tyr at position 50, which may enhance affinity by contacting the CLR turret loop, similar to a Phe at this position. A frog CGRP has Ser at position 36, and its (27-37) fragment exhibited nanomolar affinity $\left(\mathrm{K}_{\mathrm{I}}=95 \mathrm{nM}\right)$ for the human CGRP receptor (Ladram et al., 2008).

The high-affinity AM and CGRP variants provided ideal backgrounds in which to add substitutions designed to probe the mechanism of RAMP-altered CLR ligand selectivity because their enhanced affinity made it easier to accurately measure $\mathrm{pK}_{\mathrm{I}}$ and apparent $\mathrm{pK}_{\mathrm{B}}$ values. We focused on substitutions at AM position 46 to probe RAMP-dependent changes in the CLR $\beta 1-\beta 2$ loop position, i.e., allostery, and on swapping the C-terminal peptide residues to probe direct RAMP-peptide contacts. In the AM Q50W background, K46L increased affinity at the CGRP receptor and decreased affinity at the $\mathrm{AM}_{1}$ receptor (Figs. 6A and $8 \mathrm{~A}$ ), and the crystal structure indicated that $\mathrm{K} 46 \mathrm{~L}$ shifted the position of the peptide C-terminal residue phenyl ring as designed (Fig. 9D). We cannot rule out the possibility that the K46L effect is due to the loss of a hydrogen bond between the K46 side chain and RAMP2 E101 (Fig. 4B), but we think this is not the case because K46L not only decreased binding to RAMP2:CLR, but also increased binding to RAMP1:CLR. In the S45W/Q50W background, K46L only increased affinity for

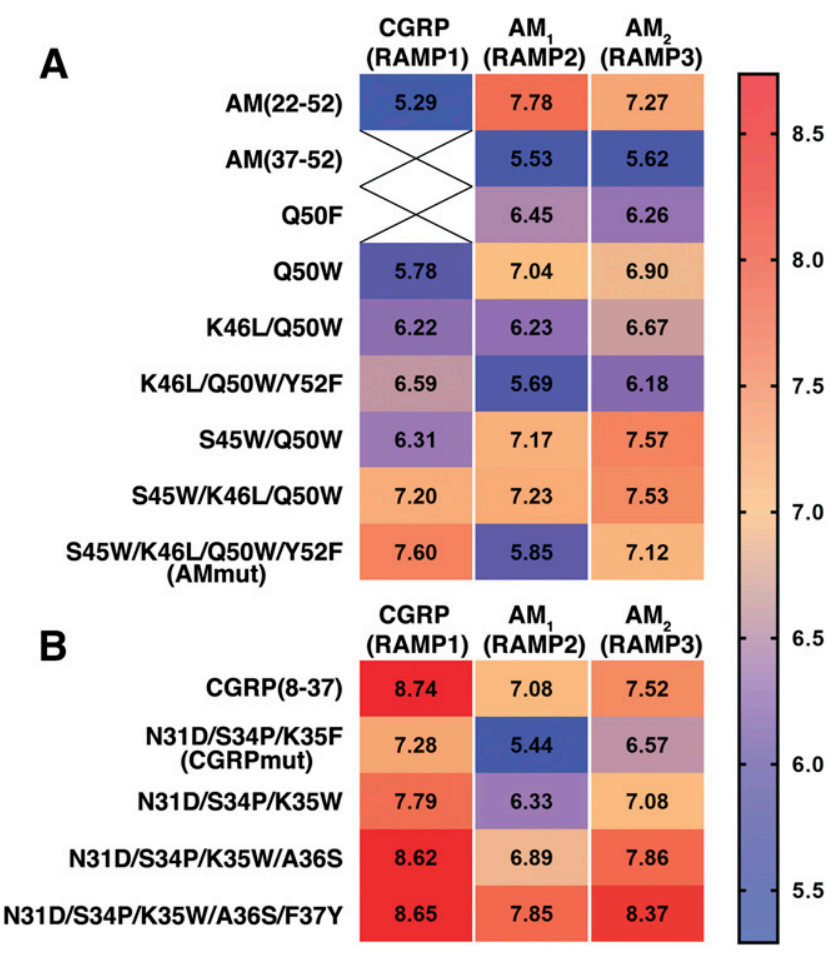

Fig. 8. Heat map summary of $A M$ and CGRP variant apparent $\mathrm{pK}_{\mathrm{B}}$ values obtained in the cell-based signaling assay in COS-7 cells. Apparent $\mathrm{pK}_{\mathrm{B}}$ values obtained for transiently expressed CGRP receptor (RAMP1), AM receptor (RAMP2), or $\mathrm{AM}_{2}$ receptor (RAMP3) stimulated with $\alpha$ CGRP (CGRP receptor) or AM (AM receptors) in the presence or absence of the indicated AM antagonist variants (A) or CGRP antagonist variants (B). $\mathrm{AM}$ variants are in the context of $\mathrm{AM}(37-52)$, whereas CGRP variants are in the context of CGRP(27-37). The mean apparent $\mathrm{pK}_{\mathrm{B}}$ values for $\mathrm{AM}(37-$ 52) and AM Q50F at the CGRP receptor were estimated to be less than 5.3 (indicated by $\mathrm{X}$ symbol). See Table 2 for apparent $\mathrm{pK}_{\mathrm{B}}$ values with associated error and Supplemental Fig. S7 and Supplemental Table S3 for statistical analysis.

RAMP1:CLR (Figs. 6A and 8A). These data are consistent with $\mathrm{K} 46 \mathrm{~L}$ causing AM to be more complementary to the shape of the RAMP1:CLR pocket occupied by the C-terminal residue. In AMmut, the $\mathrm{C}$-terminal residue swap $\mathrm{Y} 52 \mathrm{~F}$ further decreased antagonism at the $\mathrm{AM}_{1}$ receptor (Fig. 8A) because loss of the Y52 side chain hydroxyl removes the ability to hydrogen bond with RAMP2 E101, and RAMP2 F111 cannot contact the remaining phenyl ring (Fig. 4A). The CGRP conformation did not lend itself to probing the RAMP allosteric effects as we did with AM, but we probed the RAMP-CGRP contacts, and these data also provide insight into allostery. Giving CGRP N31D/S34P/K35W/A36S the ability to hydrogen bond with RAMP2 E101 via the F37Y substitution enhanced its ability to bind $\mathrm{AM}_{1}$, but it clearly still preferred the CGRP receptor (Figs. 6B and $8 \mathrm{~B}$ ). This result is probably due to RAMP1/2-dependent conformational differences in CLR because only the CGRP C-terminal residue contacts the RAMP. Altogether, our data are consistent with the hypothesis that RAMPs determine CLR ligand selectivity through a dual mechanism comprising distinct contacts with the peptide $\mathrm{C}$-terminal residue and subtle allosteric effects on CLR conformation. There are also data suggesting an allosteric component to RAMP function at the related calcitonin receptor (Gingell et al., 2016; Lee et al., 2016). 
A

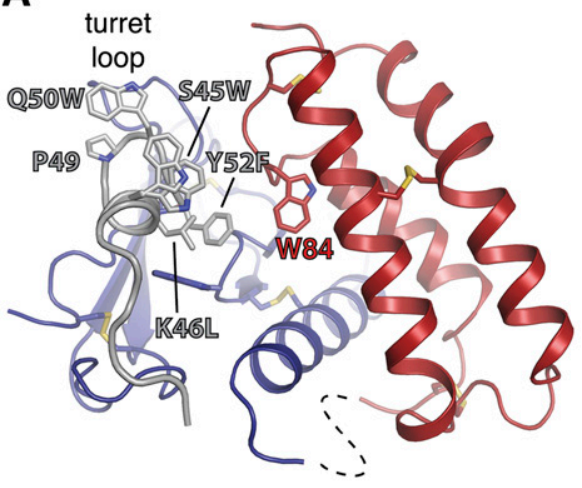

B

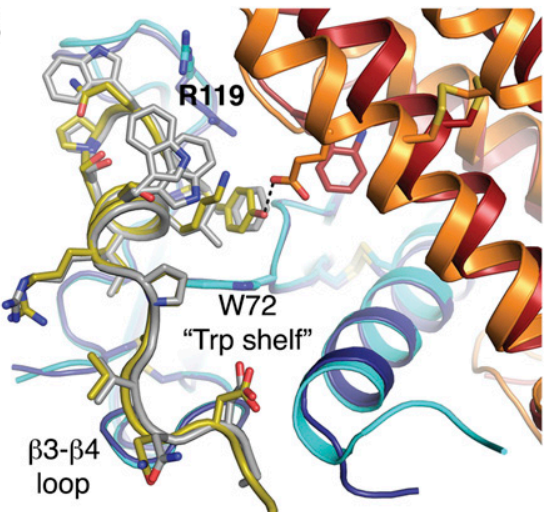

AMmuti RAMP1-CLR

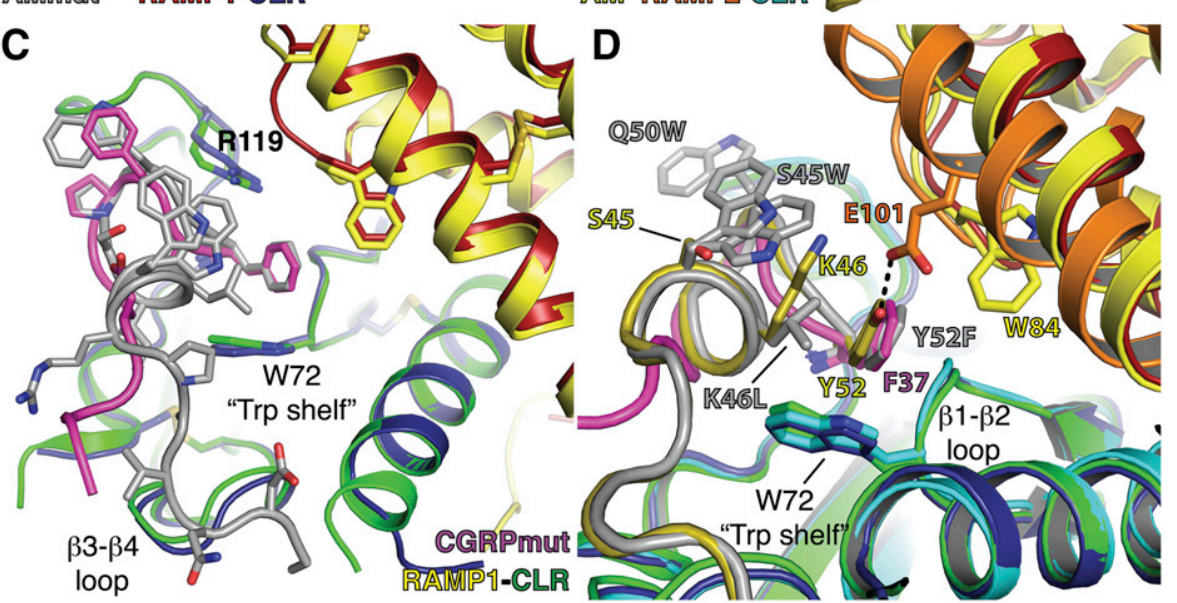

Fig. 9. Structural basis for AMmut binding to the RAMP1-CLR ECD complex. (A) Cartoon representation of the 2.8- $\AA$ resolution crystal structure of AMmut-bound MBP-RAMP1-CLR ECD with AMmut in gray, CLR ECD in blue, and RAMP1 ECD in red. Two alternate conformations were modeled for $\mathrm{S} 45 \mathrm{~W}$. The $(\mathrm{GSA})_{3}$ linker sequence connecting the two ECDs was disordered. MBP is omitted for clarity. (B) Superimposition of AMmut-bound RAMP1-CLR ECD [colored as in (A)] and AM (gold) bound to RAMP2 ECD (orange)-CLR ECD (cyan) (Protein Data Bank 4RWF). (C) Superimposition of AMmutbound RAMP1-CLR ECD [colored as in (A)] and CGRPmut (violet) bound to RAMP1 ECD (yellow)-CLR ECD (green) (Protein Data Bank 4RWG). (D) Detailed view comparing peptidebinding interactions for the three peptide-bound RAMP ECD-CLR ECD heterodimer crystal structures (current structure and Protein Data Bank 4RWF and 4RWG). Key peptide and RAMP residues are labeled and colored as in (A)-(C).
It is informative to compare the ECD complex-binding data (Fig. 6) and the cell-based antagonism data (Fig. 8). For the CGRP variants, there was good agreement between the $\mathrm{pK}_{\mathrm{I}}$ and $\mathrm{pK}_{\mathrm{Bapp}}$ values for RAMP1:CLR, suggesting that the binding determinants for these peptides reside mostly within the ECD. In contrast, the CGRP variants bound intact RAMP2:CLR in cells better than the tethered RAMP2-CLR ECD, and as a consequence, they were less selective in the cellbased assay than in the FP assay (Tables 1 and 2). For the AM variants, the relationship between the ECD binding and cellbased antagonism results was more complex. Some variants did not differentiate RAMP1-CLR ECD and RAMP2-CLR ECD, but preferred intact RAMP2:CLR over RAMP1:CLR (e.g., Q50W and S45W/Q50W). Consequently, whereas adding K46L into these variants caused them to prefer RAMP1-CLR ECD over RAMP2-CLR ECD, they became nonselective for intact RAMP1:CLR and RAMP2:CLR. AM(37-52)-based variants may be at a disadvantage at full-length RAMP1:CLR because their $\mathrm{N}$-terminal region occupies the ECD complex differently than CGRP(27-37) (Fig. 9C). Similar to the CGRP variants, the AM variants were less selective in the cell-based assay than in the FP assay. The divergence in the degree of receptor selectivity between the ECD-binding and signaling data may be due to complexity in the intact receptors. The orientation of the ECD complex with respect to the remainder of the receptor within the full-length complexes is unknown, and portions of the membraneembedded domains may also contact the C-terminal "ECDbinding" half of the peptides (Zhang et al., 2017). In addition, the ECD complexes were expressed in $E$. coli so they are not $N$-glycosylated, which might affect peptide binding as for the related calcitonin receptor (Lee et al., 2017; Liang et al., 2017). Despite some disagreement in the degree of receptor selectivity, the relative activities of the AM/CGRP variants were reasonably consistent across the two assays.

The cell-based data provide insight into the molecular determinants of ligand binding at the $\mathrm{AM}_{2}$ receptor, for which we lack the purified RAMP3-CLR ECD complex and a crystal structure. The two AM receptors are very similar, but there is evidence for distinct $\mathrm{AM}_{1} / \mathrm{AM}_{2}$ agonist-binding site properties (Watkins et al., 2016). Our data are consistent with these findings even for short antagonist fragments that are expected to primarily bind the ECD complex. Notably, AMmut discriminated the AM receptors with $\sim 19$-fold selectivity, which is better than existing antagonists, although still not ideal for use as a tool. The AMmut C-terminal Phe probably did not decrease binding to $\mathrm{AM}_{2}$ because RAMP3 appears to be a RAMP1/2 hybrid in terms of how it augments the CLR pocket. RAMP3 W84 and E74 enable contact with peptides having either a C-terminal Phe or Tyr (Supplemental Fig. S10). The $\mathrm{AM}_{1} / \mathrm{AM}_{2}$-discriminating ability of AMmut appears to result in part from the ability of its C-terminal Phe to contact RAMP3 W84, but not RAMP2 F111. The conserved RAMP1/3 residue W84 suggests that peptide design strategies that seek to discriminate the RAMP1 and RAMP3 complexes may benefit from exploiting the putative allosteric effects of RAMPs rather than RAMP-peptide contacts. 
This study highlights the challenge of developing peptides that strongly discriminate the CGRP, $\mathrm{AM}_{1}$, and $\mathrm{AM}_{2}$ receptors when starting from peptides that primarily bind CLR. Nonetheless, we developed short AM and CGRP variants with significantly enhanced affinities, and we were able to swap the selectivity of $\mathrm{AM}$ for the CGRP and $\mathrm{AM}_{1}$ receptors with the AMmut variant. The dramatically altered receptor binding preferences of AMmut resulted from substitutions designed to exploit the differences in how RAMP1 and RAMP2 both augment the CLR pocket and alter its shape. These results support a dual mechanism for RAMP function in which direct contact with the peptide C-terminal residue and allosteric modulation of CLR cooperate to determine ligand selectivity. The novel peptide variants developed herein and the new crystal structure should help guide future efforts to develop potent and selective AM/CGRP-based pharmacological tools and therapeutics.

\section{Acknowledgments}

The authors thank Joe Brunzelle for assistance with remote data collection at beamline 21-ID-G (LS-CAT) of the Advanced Photon Source.

\section{Authorship Contributions}

Participated in research design: Booe, Hay, Pioszak.

Conducted experiments: Booe, Warner, Roehrkasse.

Performed data analysis: Booe, Warner, Hay, Pioszak.

Wrote or contributed to the writing of the manuscript: Booe, Hay, Pioszak.

\section{References}

Adams PD, Afonine PV, Bunkóczi G, Chen VB, Davis IW, Echols N, Headd JJ, Hung LW, Kapral GJ, Grosse-Kunstleve RW, et al. (2010) PHENIX: a comprehensive Python-based system for macromolecular structure solution. Acta Crystallogr D Biol Crystallogr 66:213-221.

Aubdool AA, Thakore P, Argunhan F, Smillie SJ, Schnelle M, Srivastava S, Alawi KM, Wilde E, Mitchell J, Farrell-Dillon K, et al. (2017) A novel $\alpha$-calcitonin gene-related peptide analogue protects against end-organ damage in experimental hypertension, cardiac hypertrophy, and heart failure. Circulation 136:367-383.

Bailey RJ and Hay DL (2006) Pharmacology of the human CGRP1 receptor in Cos 7 cells. Peptides 27:1367-1375.

Barwell J, Gingell JJ, Watkins HA, Archbold JK, Poyner DR, and Hay DL (2012) Calcitonin and calcitonin receptor-like receptors: common themes with family B GPCRs? Br J Pharmacol 166:51-65.

Booe JM, Walker CS, Barwell J, Kuteyi G, Simms J, Jamaluddin MA, Warner ML, Bill RM, Harris PW, Brimble MA, et al. (2015) Structural basis for receptor activity-modifying protein-dependent selective peptide recognition by a $\mathrm{G}$ proteincoupled receptor. Mol Cell 58:1040-1052.

Caron KM and Smithies O (2001) Extreme hydrops fetalis and cardiovascular abnormalities in mice lacking a functional Adrenomedullin gene. Proc Natl Acad Sci USA 98:615-619.

Chiba T, Yamaguchi A, Yamatani T, Nakamura A, Morishita T, Inui T, Fukase M, Noda T, and Fujita T (1989) Calcitonin gene-related peptide receptor antagonist human CGRP-(8-37). Am J Physiol 256:E331-E335.

Dackor RT, Fritz-Six K, Dunworth WP, Gibbons CL, Smithies O, and Caron KM (2006) Hydrops fetalis, cardiovascular defects, and embryonic lethality in mice lacking the calcitonin receptor-like receptor gene. Mol Cell Biol 26 $2511-2518$.

Edvinsson L (2015) CGRP receptor antagonists and antibodies against CGRP and its receptor in migraine treatment. Br J Clin Pharmacol 80:193-199.

Edvinsson L (2017) The trigeminovascular pathway: role of CGRP and CGRP receptors in migraine. Headache $\mathbf{5 7}$ (Suppl 2):47-55.

Emsley P, Lohkamp B, Scott WG, and Cowtan K (2010) Features and development of Coot. Acta Crystallogr D Biol Crystallogr 66:486-501.

Fritz-Six KL, Dunworth WP, Li M, and Caron KM (2008) Adrenomedullin signaling is necessary for murine lymphatic vascular development. J Clin Invest 118:40-50.
Gingell J, Simms J, Barwell J, Poyner DR, Watkins HA, Pioszak AA, Sexton PM, and Hay DL (2016) An allosteric role for receptor activity-modifying proteins in defining GPCR pharmacology. Cell Discov 2:16012.

Gruber CW, Muttenthaler M, and Freissmuth M (2010) Ligand-based peptide design and combinatorial peptide libraries to target G protein-coupled receptors. Curr Pharm Des 16:3071-3088.

Hay DL and Pioszak AA (2016) Receptor activity-modifying proteins (RAMPs): new insights and roles. Annu Rev Pharmacol Toxicol 56:469-487.

Kato J and Kitamura K (2015) Bench-to-bedside pharmacology of adrenomedullin. Eur J Pharmacol 764:140-148.

Klein KR and Caron KM (2015) Adrenomedullin in lymphangiogenesis: from development to disease. Cell Mol Life Sci 72:3115-3126.

Kusano S, Kukimoto-Niino M, Hino N, Ohsawa N, Okuda K, Sakamoto K, Shirouzu M, Shindo T, and Yokoyama S (2012) Structural basis for extracellular interactions between calcitonin receptor-like receptor and receptor activity-modifying protein 2 for adrenomedullin-specific binding. Protein Sci 21(2):199-210.

Ladram A, Besné I, Breton L, de Lacharrière O, Nicolas P, and Amiche M (2008) Pharmacologic study of C-terminal fragments of frog skin calcitonin gene-related peptide. Peptides 29:1150-1156.

Lee SM, Booe JM, Gingell JJ, Sjoelund V, Hay DL, and Pioszak AA (2017) $\mathrm{N}$-Glycosylation of asparagine 130 in the extracellular domain of the human calcitonin receptor significantly increases peptide hormone affinity. Biochemistry $\mathbf{5 6}$ : 3380-3393.

Lee SM, Hay DL, and Pioszak AA (2016) Calcitonin and amylin receptor peptide interaction mechanisms: insights into peptide-binding modes and allosteric modulation of the calcitonin receptor by receptor activity-modifying proteins. J Biol Chem 291:8686-8700.

Liang YL, Khoshouei M, Radjainia M, Zhang Y, Glukhova A, Tarrasch J, Thal DM Furness SGB, Christopoulos G, Coudrat T, et al. (2017) Phase-plate cryo-EM structure of a class B GPCR-G-protein complex. Nature 546:118-123.

McCoy AJ, Grosse-Kunstleve RW, Adams PD, Winn MD, Storoni LC, and Read RJ (2007) Phaser crystallographic software. J Appl Cryst 40:658-674

McLatchie LM, Fraser NJ, Main MJ, Wise A, Brown J, Thompson N, Solari R, Lee MG, and Foord SM (1998) RAMPs regulate the transport and ligand specificity of the calcitonin-receptor-like receptor. Nature 393:333-339.

Moad HE and Pioszak AA (2013) Selective CGRP and adrenomedullin peptide binding by tethered RAMP-calcitonin receptor-like receptor extracellular domain fusion proteins. Protein Sci 22(12):1775-1785.

Otwinowski Z and Minor W (1997) Processing of X-ray diffraction data collected in oscillation mode. Methods Enzymol 276:307-326.

Rist B, Entzeroth M, and Beck-Sickinger AG (1998) From micromolar to nanomolar affinity: a systematic approach to identify the binding site of CGRP at the human calcitonin gene-related peptide 1 receptor. J Med Chem 41:117-123.

Roehrl MH, Wang JY, and Wagner G (2004) A general framework for development and data analysis of competitive high-throughput screens for small-molecule inhibitors of protein-protein interactions by fluorescence polarization. Biochemistry 43:16056-16066.

Russell FA, King R, Smillie SJ, Kodji X, and Brain SD (2014) Calcitonin gene-related peptide: physiology and pathophysiology. Physiol Rev 94:1099-1142

Russo AF (2015) Calcitonin gene-related peptide (CGRP): a new target for migraine. Annu Rev Pharmacol Toxicol 55:533-552.

Shindo T, Kurihara Y, Nishimatsu H, Moriyama N, Kakoki M, Wang Y, Imai Y, Ebihara A, Kuwaki T, Ju KH, et al. (2001) Vascular abnormalities and elevated blood pressure in mice lacking adrenomedullin gene. Circulation 104:1964-1971. ter Haar E, Koth CM, Abdul-Manan N, Swenson L, Coll JT, Lippke JA, Lepre CA, Garcia-Guzman M, and Moore JM (2010) Crystal structure of the ectodomain complex of the CGRP receptor, a class-B GPCR, reveals the site of drug antagonism. Structure 18:1083-1093.

Tso AR and Goadsby PJ (2017) Anti-CGRP monoclonal antibodies: the next era of migraine prevention? Curr Treat Options Neurol 19:27.

Warner ML, Bell T, and Pioszak AA (2015) Engineering high-potency R-spondin adult stem cell growth factors. Mol Pharmacol 87:410-420.

Watkins HA, Au M, Bobby R, Archbold JK, Abdul-Manan N, Moore JM, Middleditch MJ, Williams GM, Brimble MA, Dingley AJ, et al. (2013) Identification of key residues involved in adrenomedullin binding to the AM1 receptor. Br J Pharmacol 169:143-155.

Watkins HA, Chakravarthy M, Abhayawardana RS, Gingell JJ, Garelja M, Pardamwar M, McElhinney JM, Lathbridge A, Constantine A, Harris PW, et al. (2016) Receptor activity-modifying proteins 2 and 3 generate adrenomedullin receptor subtypes with distinct molecular properties. J Biol Chem 291:11657-11675.

Zhang Y, Sun B, Feng D, Hu H, Chu M, Qu Q, Tarrasch JT, Li S, Sun Kobilka T, Kobilka BK, et al. (2017) Cryo-EM structure of the activated GLP-1 receptor in complex with a G protein. Nature 546:248-253.

Address correspondence to: Augen A. Pioszak, Department of Biochemistry and Molecular Biology, The University of Oklahoma Health Sciences Center, 975 N.E. 10th St., Oklahoma City, OK 73104. E-mail: augen-pioszak@ouhsc. edu 